\title{
Evaluation of microstructure anisotropy on room and medium temperature ECAP deformed F138 steel
}

\author{
N.S. De Vincentis ${ }^{\mathrm{a}, *}$, A. Kliauga ${ }^{\mathrm{b}}$, M. Ferrante ${ }^{\mathrm{b}}$, M. Avalos ${ }^{\mathrm{a}}$, H.-G. Brokmeier $^{\mathrm{c}}$, R.E. Bolmaro ${ }^{\mathrm{a}}$ \\ ${ }^{a}$ Instituto de Física Rosario, FCEIA-UNR-CONICET, BV. 27 de Febrero 210 bis, S2000EZP Rosario, Argentina \\ ${ }^{\mathrm{b}}$ Departamento de Engenharia de Materiais - Universidade Federal de São Carlos, Rodovia Washington Luís, km 235 - SP-310, São Carlos, SP $13565-905$, Brazil

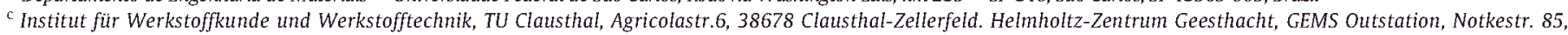 \\ 22607 Hamburg, Germany
}

\section{A R T I C L E I N F O}

\section{Article history:}

Received 15 January 2015

Received in revised form 27 May 2015

Accepted 29 June 2015

Available online 2 July 2015

\section{Keywords:}

Microstructure anisotropy

SPD

Williamson-Hall

Convolutional Multiple Whole Profile

EBSD

\begin{abstract}
A B S T R A C T
The microstructure developed during severe plastic deformation results in improved mechanical properties because of the decrease in domain sizes and accumulation of defects, mainly dislocation arrays. The characteristic deformation stages observed in low stacking fault energy (SFE) face centered cubic (FCC) materials are highly influenced by the development of the primary and secondary twinning that compete with dislocation glide. In this paper, a low SFE F138 stainless steel is deformed by equal channel angular pressing (ECAP) up to 4 passes at room temperature (RT) and at $300{ }^{\circ} \mathrm{C}$ to compare the grain refinement and twin boundary development with increasing deformation. Tensile tests were performed to determine the deformation stages reached by the material before and after ECAP deformation, and the resulting microstructure was observed by TEM. X-ray diffraction and EBSD, average technique the first and local the second one, were used to quantify the microstructural changes, allowing the determination of diffraction domain sizes, dislocation and stacking fault densities and misorientation indices, which lead to a complete analysis of the deformation introduced in the material, with comparative correlations between various microstructural parameters.
\end{abstract}

(c) 2015 Elsevier Inc. All rights reserved.

\section{Introduction}

Bulk nanostructured materials, with improved mechanical properties, can be produced by introducing very large deformations at high strain rates through severe plastic deformation (SPD) techniques [1]. The conventional material deformation processes can also introduce large plastic strains, but with the consequence of changing the sample dimensions in undesirable ratios, which limits both the level of deformation that can be achieved and the industrial application of the deformed material; however, the SPD techniques preserve at least some of the sample dimensions, allowing to repeat the deformation process several times, increasing the deformation level and favoring grain refinement.

In FCC metals with low SFE, like $\mathrm{Cu}-\mathrm{Zn}$ and $\mathrm{Cu}-\mathrm{Al}$ alloys, austenitic stainless steel and silver, twinning becomes also a deformation mechanism allowing to achieve ultra-fine grain structures by means of SPD, and promoting a Hall-Petch effect during strain hardening. Asgari et al. [2] and El-Danaf et al. [3] reported that low SFE FCC metals exhibit four distinct strain-hardening stages in simple compression tests. They correlated different

\footnotetext{
* Corresponding author.

E-mail address: devincentis@ifir-conicet.gov.ar (N.S. De Vincentis).
}

strain hardening rates with the activation of different deformation mechanisms:

- stage A, similar to deformation stage III, correlated with multiple dislocation slip;

- stage $B$, correlated with the initiation of twinning deformation after an accumulation of certain critical dislocation density. For materials with SFE varying from 7 to $14 \mathrm{~mJ} / \mathrm{m}^{2}$ this stage corresponds to a $\left(\sigma_{\mathrm{w}}-\sigma_{0} / G\right) \sim 0.003,\left(\sigma_{0}\right.$ is the yielding stress and $\sigma_{\mathrm{w}}$ the stress to twin initiation) and a constant strain-hardening rate at about 0.02 to $0.03 \mathrm{G}$;

- stage $C$, correlated with a decreasing rate of primary twinning and a strong competition between twining and slip; and

- stage $D$, reflecting the accumulation of sufficient stress allowing the activation of secondary twin for shearing pre-existing twins. It is characterized by the presence of extensive twin intersections. For different low SFE materials this occurs at a strain-hardening rate of about 0.007 to $0.001 \mathrm{G}$ (larger than the typical stage IV exhibited by medium and high SFE cubic metals). The value of SFE had only a negligible influence on the stress required to produce twin intersections. They also observed that the twin initiation was shifted to higher stress values when the grain size decreased, and was suppressed when grain size was reduced from 40 to $9 \mu \mathrm{m}$. Similar results were obtained by Ueji et al. [4] and Gutierrez-Urrutia et al. [5] in TWIP steels. 
They observed that twinning was more difficult to activate when grain size was reduced to $3-2 \mu \mathrm{m}$ and that, as grain size was reduced, the influence of the resolved shear stress increased. Bagherpour et al. [6,7] studied TWIP steel samples deformed by ECAP and SSE (simple shear extrusion), observing in the latter case an increase in twin density with higher cumulative strain, and a submicron grain size.

Composition, temperature and strain rate have great influence on the deformation mechanisms because they influence the SFE, the flow stress and the dislocation annihilation rate. Rising the temperature increases the SFE and twin formation is inhibited $[8,9]$. For example $H$. Ueno et al. [10] observed the deformation microstructure of an ECAP deformed SUS 316L austenitic stainless steel: twins were formed until $150^{\circ} \mathrm{C}$ and above $200^{\circ} \mathrm{C}$ only dislocation glide was observed. For $\mathrm{Cu}$ and $\mathrm{Cu}-\mathrm{Al}$ alloys, Y. Zhang et al. [11] observed that at RT the influence of Al content in decreasing the stacking fault energy was evidently changing the deformation mechanism from dislocation glide to twinning at a SFE below $45 \mathrm{~mJ} / \mathrm{m}^{2}$; whereas at liquid nitrogen temperature and high deformation rates, independently of $\mathrm{Al}$ content, the active deformation mechanism was always twinning. When twinning is active, the initial grain is divided in twin lamellae, and further fragmentation occurs either by formation of dislocation cells inside the lamellae or by formation of shear bands and twin intersection with resulting grain size of the same order of the twin lamellae thickness. Similar behavior was also observed in TWIP steels deformed at different temperatures; Timokhina et al. [12] performed ECAP deformation at $200^{\circ} \mathrm{C}, 300^{\circ} \mathrm{C}$ and $400^{\circ} \mathrm{C}$ up to 4 cycles and observed twins after each stage (micro and nano-twins) except for $1 \mathrm{cycle}$ at $400^{\circ} \mathrm{C}$, and the different microstructural characteristics obtained at different deformation degrees affected both the strain-hardening behavior and the mechanical properties.

The F138 alloy is a modified 316L austenitic stainless steel with $14 \%$ $\mathrm{Ni}, 17 \% \mathrm{Cr}$ and $2.8 \%$ Mo and has an estimated SFE of $32 \mathrm{~mJ} / \mathrm{m}^{2}$ at RT. Its deformation behavior at RT corresponds to the features described above. Scheriau et al. [13] observed that at the initial stage of severe plastic shear deformation the microstructure is characterized mainly by two deformation modes: mechanical twinning and submicronscaled shear banding. The former leads to profuse mechanical twins with 10 to $20 \mathrm{~nm}$ in thickness and the latter divides the material into a debris-like structure leading to micron-sized blocks of Twin-Matrix (TM) lamellae. For very large strains by high pressure torsion, the initial coarse structural elements were transformed in a very homogeneous nanocrystalline microstructure. In some regions of the microstructure a pronounced curvature of the TM lamellae was observed which was attributed to the alignment via simple rotation of the lamellae parallel to the deformation direction; it was assumed that the just developed TM lamellae would be gradually fragmented into small structures with further deformation. Similar conclusions were presented by Liu et al. [14] in 316L steel deformed by dynamic plastic deformation, where the resulting structure consisted in austenitic micro-grains embedded in nano-twin bundles; this microstructure conferred the steel a yield strength almost five times larger than the corresponding value for the as-received coarse-grained structure.

The present paper aims to characterize the microstructure of an austenitic stainless steel with low SFE at increasing Von Mises deformation and at two different temperatures. For this characterization to be complete it is necessary to gather information at different scales, combining bulk microstructural properties with local misorientation information. For the former analysis, X-ray diffraction (XRD) was considered the most suitable technique because it provides average values of the microstructural characteristics that represent the full bulk sample [15,16]. Electron backscatter diffraction (EBSD) [17] was used for the latter analysis, because it does not only allow to observe the resulting microstructure after the deformation process but also reports the orientation of each grain or subgrain and the misorientation between them. TEM images were also obtained in order to observe the features requiring higher resolution.

\section{Methods of deformation analysis}

\subsection{Electron backscatter diffraction (EBSD)}

For the local analysis, EBSD provides orientation and misorientation information in addition to grain size distribution and topology. This technique consists in scanning an area on the surface of a material, capturing and identifying point-by-point the corresponding Kikuchi patterns, which contain information on the crystallographic orientation of that point. The Orientation Imaging Microscopy (OIM-EDAX $®$ ) software also allows the calculation of misorientations between pairs of neighboring points, either in the same kernel or grain, as a mean to characterize the deformation level of the grains; it also allows to quantify borders of high-angle and low-angle misorientations and CSL, the average misorientation in a specified kernel or grain, or to estimate the size and shape of crystallographic domains, among other applications. The only dislocations whose presence the method can so far infer are the ones arranged into misorientation boundaries, because in that condition they cause a curvature large enough $\left(>0.5^{\circ}\right)$ in the crystallographic net. The derived quantities used to characterize this situation give extra information on the dislocation distributions and subcells, complementing the information gathered using XRD and ensuring a deeper knowledge on the micro-nano structure developed by deformation.

\subsection{X-ray diffraction}

XRD analysis allows the evaluation of microstructural changes in a material by certain characteristics of the diffraction peaks: residual stresses affect their position, preferential orientations modify their intensity, and deformation affects peak broadening. Micromechanical models have been developed to estimate the correlation between peak broadening and average microstructural characteristics of a material, some of which are more prone to be used either for qualitative or quantitative analyses. Following Scherrer [18], one of the first developed models was the Williamson-Hall (W-H) method [19], which allowed to estimate the average diffraction domain size and microstrains; this model was later modified to include stacking fault influence in the determination of an effective domain size by Warren [20] and, more recently, to estimate the dislocation density and low angle boundaries by Ungár $[15,16,21,22]$. The latter modifications require the introduction of a dislocation contrast factor, which depends on the relative orientation of the burgers and line vectors of the dislocations and the diffraction vector, and on the dislocation character (edge or screw). This contrast factors have been calculated for hexagonal [23] and cubic [22] materials containing pure edge or pure screw dislocations. The relationship between peak broadening and deformation according to the Modified Williamson-Hall method is presented in Eq. (1), where $\theta, \lambda$ and $b$ are the Bragg angle, the radiation wave length and the Burgers vector, respectively. The term $\beta W_{h k l}$ represents the stacking fault contribution to line broadening: $\beta$ is the stacking fault density and $W_{h k l}$ are the Warren constants. The domain size contribution to peak broadening is $1 / \mathrm{d}$, where $\mathrm{d}$ is proportional to the volume weighted domain size, and it is independent of $h k l$. The quadratic term on $2 \sin (\theta) / \lambda$ is the strain term, where $M$ is a constant proportional to the effective outer cut-off radius of dislocations, $\rho$ is the dislocation density and $C_{A v}$ is the average contrast factor of dislocations.

$$
\text { Breadth } \begin{aligned}
\cos (\theta) / \lambda-\beta W_{h k l}= & 1 / \mathrm{d} \\
& +\left(\pi \mathrm{M}^{2} \mathrm{~b}^{2} / 2\right) \rho^{1 / 2} \mathrm{C}_{\mathrm{Av}, \mathrm{hkl}}(2 \sin (\theta) / \lambda)^{2} .
\end{aligned}
$$

In the past few years another method was developed by Ungár and Ribárik to model microstructure development by whole powder pattern fitting; the Convolutional Multiple Whole Profile (CMWP) method creates a pattern based on initial microstructural parameters to fit the model to the experimental pattern [24]. The results obtained through 
this method are considered to be more reliable for a quantitative analysis than the ones obtained using $\mathrm{W}-\mathrm{H}$ equation, what is related to the assumptions made in line breadth methods (such as $\mathrm{W}-\mathrm{H}$ and $\mathrm{W}-\mathrm{A}$ ), such as the Voigt or pseudoVoigt character of the size and strain diffraction profiles, or the validity of the assumptions that size, strain and stacking fault contributions to line breadth are simply additive [25]. Under those considerations, breadth methods are still accepted for a qualitative analysis.

By the CMWP procedure the theoretically calculated profile functions are convoluted for Domain Size $\left(\mathrm{I}^{\mathrm{DS}}\right)$, Strain $\left(\mathrm{I}^{\mathrm{S}}\right)$, Stacking Faults and/or Twins $\left(\mathrm{I}^{\mathrm{T}}\right)$ and Instrumental broadening $\left(\mathrm{I}^{\mathrm{Inst}}\right)$, together with a BackGround fitting ( $\left.{ }^{\mathrm{BG}}\right)[26,27]$. The experimental diffraction pattern $\left({ }^{\mathrm{Exp}}\right)$ is modeled through a Levenberg-Marquardt leastsquares algorithm as:

$I^{E x p}=I^{D S * I^{S} * I^{T} * I^{I n s t}+I^{B G}}$

where "**" stands for convolution.

Besides the contribution of Domain Size, which is reflected on the first term of the Fourier analysis, there is also a contribution of the microstrain given by the Fourier coefficients $[15,28]$ :

$A^{D}(L)=\exp \left(-2 \pi^{2} L^{2} K^{2}<\varepsilon_{\mathbf{g}, L}{ }^{2}>\right)$

$<\varepsilon_{\mathrm{gl}}{ }^{2}>$ is the mean square strain for dislocated crystals, which is given by the Wilkens function $f(\eta)[29]$ :

$<\varepsilon_{\mathrm{g}, \mathrm{L}}{ }^{2}>=\left(\left(\rho C \mathrm{~b}^{2}\right) / 4 \pi\right) \mathbf{f}(\eta)$

where $\rho$ is the average dislocation density, $C$ is the contrast factor, $\eta=L / R_{e}$ with $L$ the Fourier variable and $R_{e}$ the effective cut-off radius of dislocations.

In the current FCC material a unique Burgers vector is available and for a random distribution of slip systems and the absence of crystallographic texture, the dislocation contrast factor can be averaged over all $h k l$ indices and the mean square strain can be calculated as:

$<\varepsilon_{\mathrm{g}, \mathrm{L}}{ }^{2}>=\left(\left(\rho \mathrm{C}_{\mathrm{AV}} \mathrm{b}^{2}\right) / 4 \pi\right) \mathbf{f}(\eta)$

where $C_{A v}$ is the average contrast factor, already defined on modified $\mathrm{W}-\mathrm{H}$ method, allowing to separate the product $\rho \mathrm{C}$ as $\rho \mathrm{C}_{\mathrm{Av}}$ and making the dislocation density $\rho$ available through the calculation. $C_{A v}$ is tabulated or calculated by ANIZC freely available software [23], whenever the texture is considered to be negligible.

Ungár and Tichy [30] have shown that if the specimen is either un-textured or if all possible slip systems are equally populated, the average contrast factors can be expressed by the fourth order polynomials of the $h k l$ indices. For cubic crystals they found:

$C=C_{h 00}\left(1-q H^{2}\right)$,

where $H^{2}=\left(h^{2} k^{2}+h^{2} l^{2}+k^{2} l^{2}\right) /\left(h^{2}+k^{2}+l^{2}\right)^{2}$.

The constants $C_{h o 0}$ are calculated on the basis of the crystallography of dislocations and from the elastic constants of the crystal [22]. The parameter $q$ is the same for all reflections and is related to the edge or screw character of the dislocations. The value of these contrast factor parameters were calculated for different materials and types of dislocations in Ungár et al. [22]. The $\mathrm{W}-\mathrm{H}$ or CMWP procedures provide values of the $q$ parameter, which usually fall between the $q$ values calculated for edge or screw dislocations, and it is "a priori" assumed that values in between those limits suggest a mixed dislocation character.

It must be taken into account that the dislocations that affect the diffraction patterns are both GNDs (Geometrically Necessary Dislocations, which are dislocations arranged into boundaries that determine a misorientation) and SSDS (Statistically Stored
Dislocations, which are stored in cell interiors), and both methods account for them through the $M$ parameter: a lower value of this parameter indicates higher compactness of dislocation arrays, which would determine GNDs, while higher values would characterize looser arrays and separated dislocations, which would be related to SSDs. However, EBSD can only detect misorientations determined by dislocation arrays; therefore, only GNDs can be studied using this technique.

\section{Experimental methods}

In the present work a homogenized F138 stainless steel with initial average grain size of $\sim 50 \mu \mathrm{m}$ was deformed by equal channel angular pressing (ECAP). This material is commonly used for nuclear power plants $[31,32]$ and biomedical applications $[33,34]$ because of its high corrosion resistance; Table 1 shows its composition.

In ECAP the sample deforms by shearing within a small volume at the intersection between two channels due to geometric constrains of the die. Owing to no substantial change in outer dimensions it is easy to repeat the pressing forming many times and get a large accumulated strain, which can be estimated by the equation:

$\varepsilon_{\mathrm{N}}=(\mathrm{N} / \sqrt{3})(2 \cot (\Phi / 2+\Psi / 2)+\Psi \operatorname{cosec}(\Phi / 2+\Psi / 2))$

where $\Phi$ and $\psi$ are the corner and the die angles, respectively, and $\mathrm{N}$ is the number of passes [35]. For the current configuration the equivalent strain per pass is about 0.67 (Fig. 1). The material was pressed up to four times at RT and at $300^{\circ} \mathrm{C}$, and consecutive passes were done with no rotation in the extrusion axis (route $A$ ), except for ECAP $2 \times, \mathrm{RT}$, that was performed by route $\mathrm{Bc}$ (with a $90^{\circ}$ rotation around $\mathrm{ED}$ between passes). The dimensions of the steel billets were $10 \mathrm{~mm}$ in diameter and $50 \mathrm{~mm}$ in length. Sub-size samples were cut for tensile tests, with a gauge length of $7 \mathrm{~mm}$ (along ED) and $3 \mathrm{~mm} \times 2 \mathrm{~mm}$ cross section area. Three tests were performed for each sample representative of each deformation stage at room temperature and at a nominal strain rate of $10^{-3} \mathrm{~s}^{-1}$, with the elongation monitored by an optical extensometer.

Other sub-size samples were cut from the ECAP samples and polished for XRD analysis. They were ground up to 800 grit paper, then polished with 9-1 $\mu \mathrm{m}$ diamond pastes and finally with $0.05 \mu \mathrm{m}$ colloidal silica. The XRD analysis was carried out at GEMS outstation, PETRA III station, DESY synchrotron radiation facility in Hamburg, Germany, with a $0.01427 \mathrm{~nm}$ wavelength and approximately $0.01^{\circ}$ angular divergence. The sample holder on the beam line is attached to a translation-rotation stage that allows the rotation of the samples every $5^{\circ}$ around the vertical axis and the measurement of the corresponding diffraction patterns at the Mar345 solid state area detector placed right after the sample in a transmission arrangement. The instrumental broadening was obtained by fitting the diffraction pattern of a $\mathrm{LaB}_{6}$ powder sample, with a thickness similar to the steel samples $(\sim 1.0 \mathrm{~mm})$. The steel samples were cut in small bars of approximately $20 \times 1.2 \times 1.2 \mathrm{~mm}^{3}$ for the analysis at DESY because the transmission geometry requires samples with small through sections to avoid extra peak broadening. These samples were also used for the EBSD analysis, in a FEI Quanta 200 FEG-SEM in the Scanning Electron Microscopy Laboratory - Centro Científico Tecnológico Rosario-CONICET, Argentina. EBSD maps were obtained from surfaces normal to TD and ND, in order to estimate the resulting size and shape of the crystals and boundary distributions. Different scans were performed on the samples: for samples pressed once and twice at both temperatures and directions, texture scans were performed over areas of $500 \times 500 \mu^{2}$ with a $500 \mathrm{~nm}$ step

Table 1

Composition of F138 stainless steel [\%] (as given by the manufacturer).

\begin{tabular}{|c|c|c|c|c|c|c|c|c|c|c|}
\hline $\mathrm{Fe}$ & $\mathrm{Cr}$ & $\mathrm{Ni}$ & Mo & Mn & $\mathrm{Si}$ & $\mathrm{Cu}$ & $\mathrm{N}$ & $C$ & $\mathrm{P}$ & $S$ \\
\hline & 17.33 & 14.31 & 2.79 & 1.79 & 0.3 & 0.09 & 0.079 & 0.015 & 0.022 & 0.002 \\
\hline
\end{tabular}


a

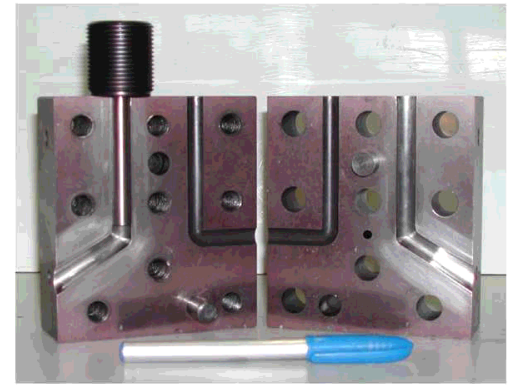

b

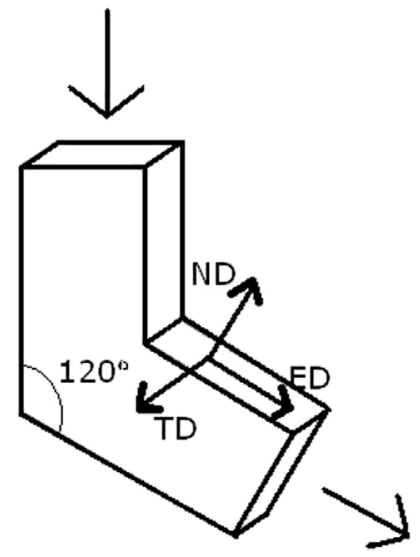

Fig. 1. a) Photo of the $120^{\circ}$ ECAP matrix and b) scheme representing the directions in the sample.

size, and detailed scans over $70 \times 70 \mu \mathrm{m}^{2}$ with a $70 \mathrm{~nm}$ step size, while samples deformed 4 times resulted in grains smaller than $50 \mu \mathrm{m}$ and could not be observed in a wide field scan, so only detailed scans were performed over $30 \times 30 \mu \mathrm{m}^{2}$ with a $40 \mathrm{~nm}$ step size. The criteria used to define a grain depended on the deformation conditions: 3 contiguous pixels were used for the samples deformed at RT, but for the samples pressed at $300^{\circ} \mathrm{C} 2$ pixels were used for 1 and 2 cycles and 5 pixels for 4 pressings; for all samples, the minimum boundary misorientation was $3^{\circ}$. This very small value, far from the usual $10^{\circ}-15^{\circ}$ used in the literature, is justified by the purpose of finding some correlation with XRD results, technique that is very sensitive to misorientations on the process of identifying grain boundaries.

Small disks of $80-100 \mu \mathrm{m}$ in thickness were also cut for TEM analysis; they were prepared by electrolytic polishing $\left(10 \% \mathrm{HClO}_{4}\right.$ in alcohol, $30 \mathrm{~V}, 0^{\circ} \mathrm{C}$ ) and then observed at a CM120 FEI microscope.

\section{Experimental results}

The mechanical properties exhibited by the samples after each deformation stage are shown in Table 2. The hardness and the yield stress increased with consecutive deformation, being lower for the samples deformed at $300{ }^{\circ} \mathrm{C}$. A large reduction was observed in the total elongation (60\% in the as-received sample down to $26 \%$

Table 2

Hardness and mechanical properties of the F138 samples.

\begin{tabular}{lcclcl}
\hline Deformation & $\sigma_{\mathrm{y}}(\mathrm{MPa})$ & $\sigma_{\mathrm{u}}(\mathrm{MPa})$ & $\varepsilon_{\mathrm{t}}(\%)$ & $\varepsilon_{\mathrm{u}}(\%)$ & $\mathrm{HV}$ \\
\hline Initial & 374 & 640 & 60 & 23 & 130 \\
$1 \times$ ECAP & 889 & 907 & 36 & 2.8 & 321 \\
$2 \times$ ECAP & 1055 & 1108 & 28 & 2.8 & 339 \\
$4 \times$ ECAP & 1140 & 1340 & 26 & 3.5 & 473 \\
$1 \times$ ECAP $300{ }^{\circ} \mathrm{C}$ & 620 & 740 & 60 & 3.0 & 270 \\
$4 \times$ ECAP $300^{\circ} \mathrm{C}$ & 915 & 1020 & 40 & 2.4 & 330 \\
\hline
\end{tabular}
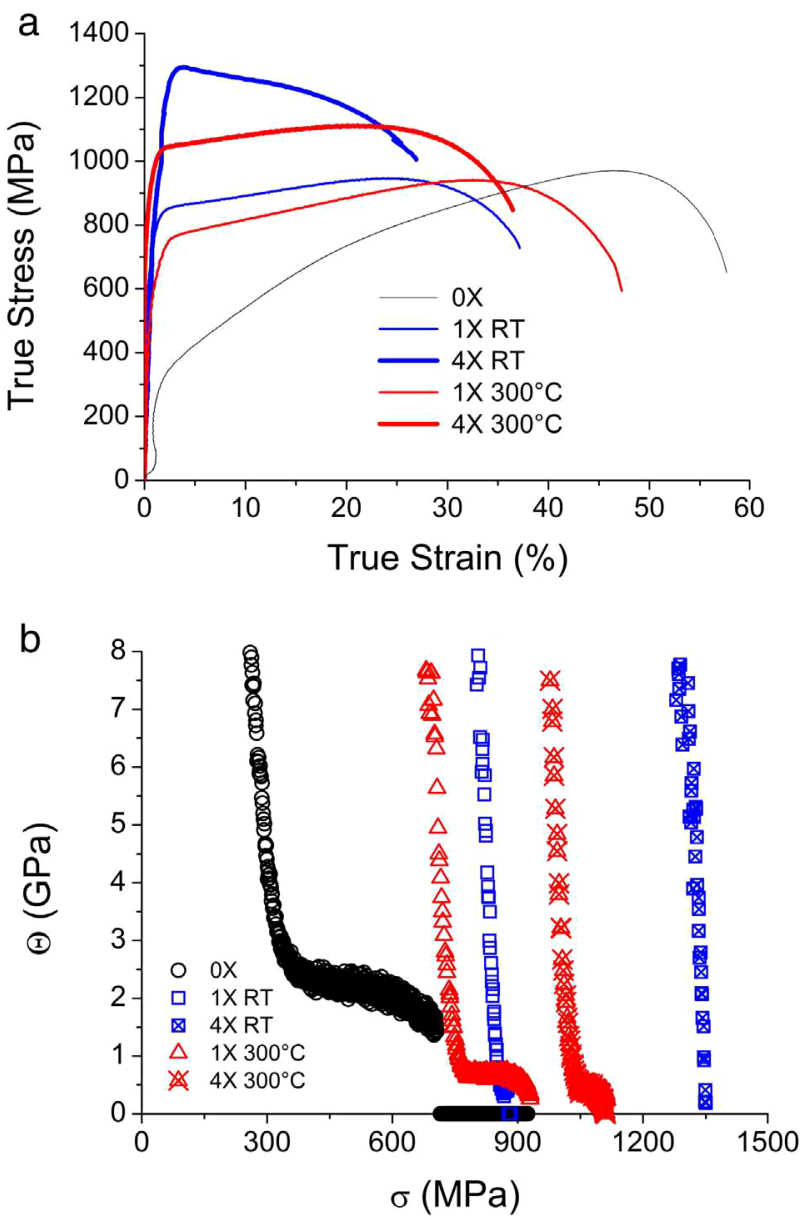

Fig. 2. (a) True stress vs. true strain and (b) strain hardening vs. true stress curves obtained for the as-received sample and deformed by ECAP at RT and $300^{\circ} \mathrm{C}$.

after four passes) but does not reduce the material ability to resist plastic deformation.

The strain hardening curves obtained from the tensile tests (Fig. 2) show that the primary and secondary twinning stages described earlier are present in the as-received sample, are shifted to higher stresses for samples deformed at $300{ }^{\circ} \mathrm{C}$ and are absent for samples deformed at room temperature. This implies that both stages have already taken place at the beginning of the deformation, and that during the ECAP process the deformation proceeds as a competition between the secondary twinning and dislocation glide, i.e. stage $C$ as described by El Danaf et al. [3].

The samples were first observed by TEM to determine with high resolution the microstructure after each deformation process. Figs. 3 to 6 show the substructures and microstructures for the samples deformed at RT. All the images were obtained through surfaces perpendicular to the transverse direction of the sample. After the first pass through the die, the original coarse grained microstructure is replaced by TM lamellae and small dislocation cells. Fig. 3(a) shows two sets of intersecting twin groups, which implies that secondary twinning has already started to take place. Four passes through this route caused a larger decrease in domain size, leading to a structure of parallel deformation bands containing nano-grains (Fig. 5(a)) and nano-twins inside some of these grains (Fig. 5(b, c)). The bands shown in Fig. 5(c) are approximately $75 \mathrm{~nm}$ wide and the separation between the twins is smaller than $5 \mathrm{~nm}$. The described microstructural features can be explained as follows: during deformation, the original macroscopic grains divide into parallel twins and high angle boundaries appear, corresponding to stages A and B, and, as deformation increases, these twins turn into deformation bands with dislocation cells and 
a

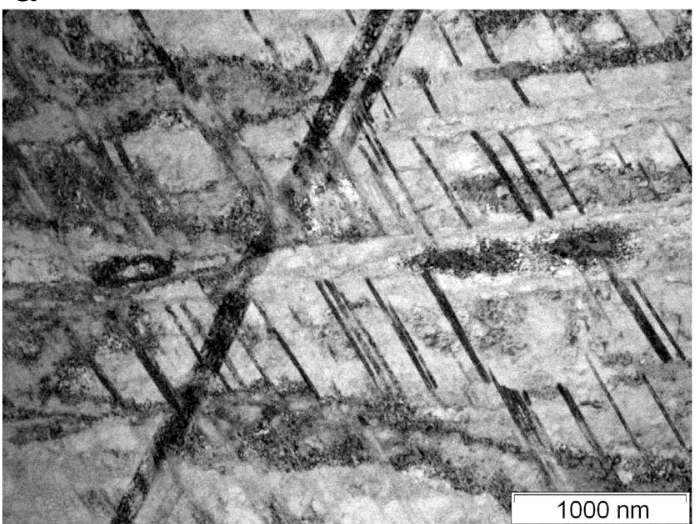

b

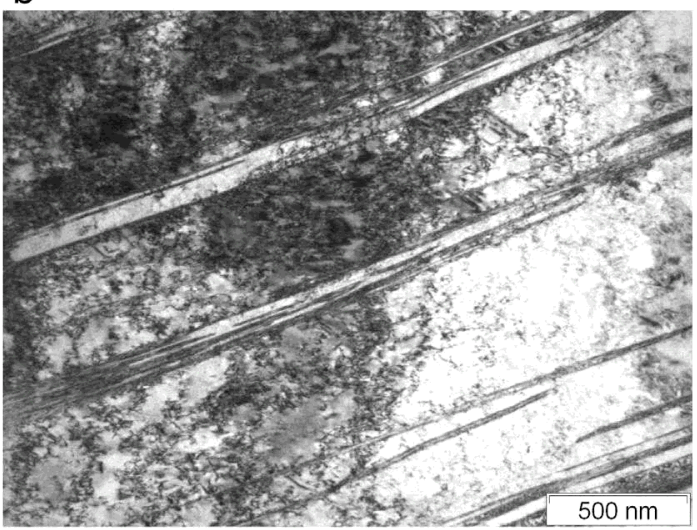

C

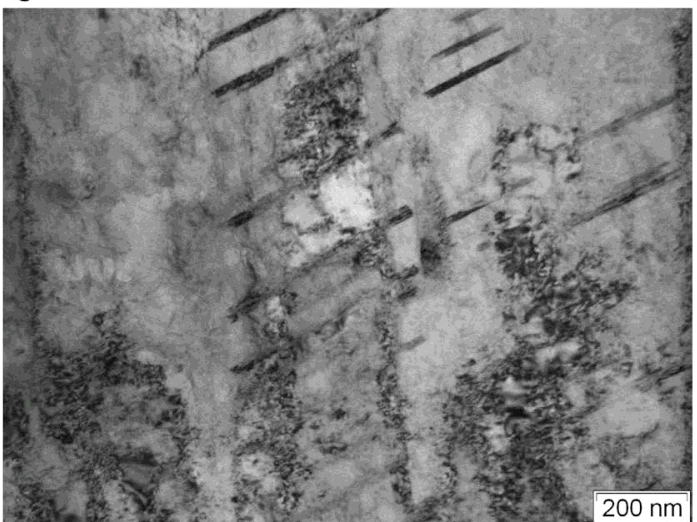

Fig. 3. TEM images showing the microstructure of the material after 1 pass of ECAP deformation at room temperature.

nano-twin bundles, which determine a nano-scale grain structure. A high dislocation density can also be appreciated in the images, which are mostly responsible for the high elastic strains that were accumulated during the ECAP process. The images that correspond to 2 ECAP cycles in route Bc (Fig. 4) show coherent areas of about $200 \mathrm{~nm}$ wide with boundaries inside them, which could correspond to low angle misorientation boundaries.

The microstructure observed after deformation at $300{ }^{\circ} \mathrm{C}$ (Fig. 6) is characterized by shear bands with dislocation cell substructures and little formation of twins, which is consistent with the increase in stacking fault energy with increasing temperature, as mentioned before. A different dislocation configuration is observed after 4 pressings at both temperatures (Figs. 5 and 6), being lower for the sample pressed at $300^{\circ} \mathrm{C}$. Images for 1 and 2 pressings at high temperature are not shown in this work. At this temperature the pace for dislocation accumulation is much slower because of the competition between a

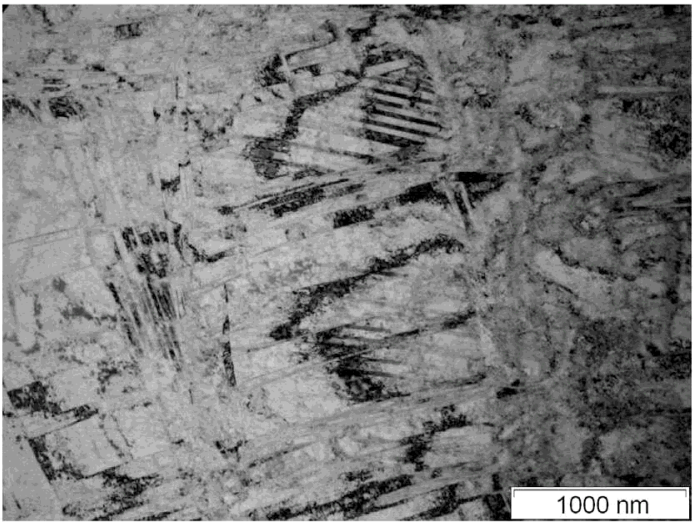

b

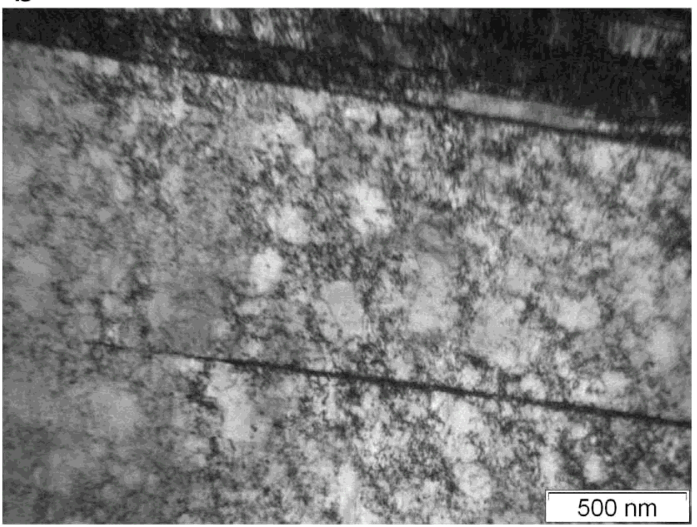

C

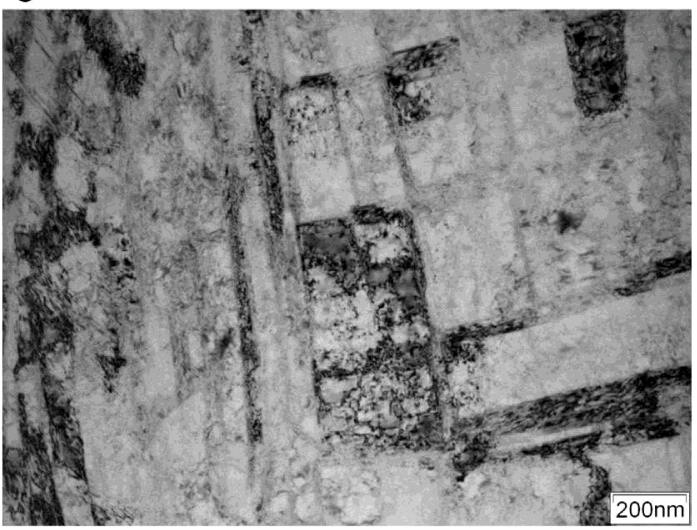

Fig. 4. TEM images showing the microstructure of the material after 2 passes of ECAP deformation at room temperature.

dislocations generated by SPD and dislocation climb and annihilation. XRD results presented later in this paper give more quantitative information regarding to this hypothesis, but in Fig. 6a)-c) it is clearly seen that dislocation density keeps low.

\subsection{EBSD}

A wider field vision and a more statistically sound approach to the microstructure can be obtained through EBSD. Their topological and local characteristics were observed in more detail to complement the results obtained by XRD. In order to study a microstructural feature of a material using EBSD, it is advisable to use a step size of about onetenth of the dimension of the mentioned feature [36]. Expected feature sizes are close to about $50 \mathrm{~nm}$, which would imply the use of a $5 \mathrm{~nm}$ step size, which exceeds the possibilities of the current state of the art of 
a

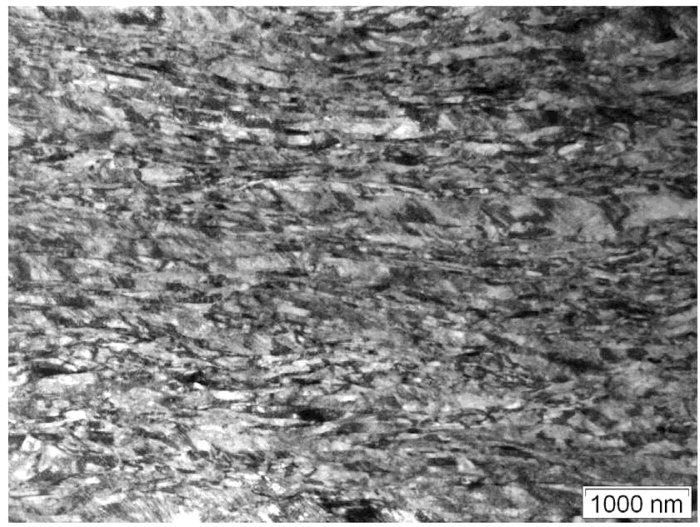

b

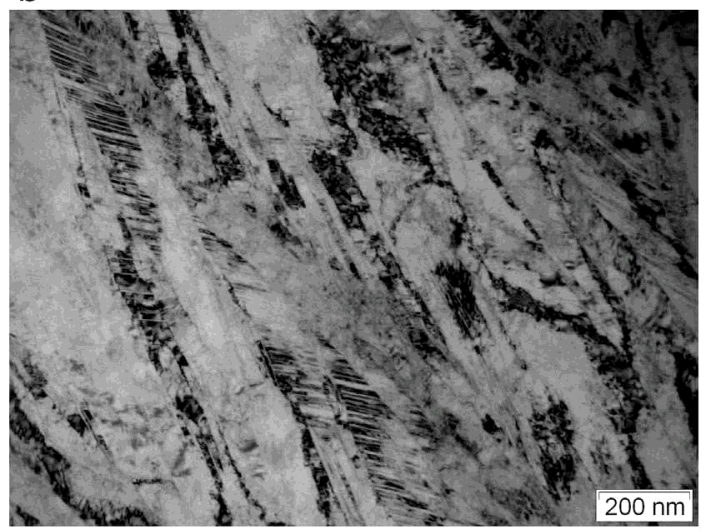

C

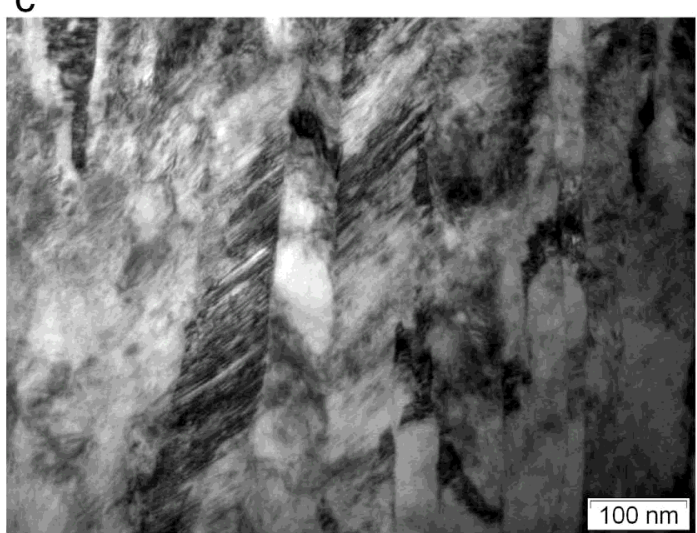

Fig. 5. TEM images showing the microstructure of the material after 4 passes of ECAP deformation at room temperature.

EBSD. However, the morphology and anisotropy might become clear after EBSD observation and it will guide the analysis.

Fig. 7 presents the inverse pole figure (IPF) maps corresponding to texture scans for $1 \times$ and $2 \times$ and detailed scans for $4 \times$. The grain refinement produced by increasing ECAP passes is evident in these images, being more evident in the samples deformed at RT.

The EBSD images show the known behavior on microstructure development by ECAP, with a diminishing angle between the ED and the main dimension of the elongated features. Whatsoever, no coincidence was found between the measured angles and the few continuum based calculations of the literature, for what it is clear the high influence exerted by twinning on the microstructural features geometry and orientation with respect to the sample axes $[37,38]$. Several scans were used to get the angle between main elongated axes of the microstructure features and the ED axes. For samples deformed through path $A$ at both temperatures, after 1 pressing the angle is $60^{\circ}$ and a

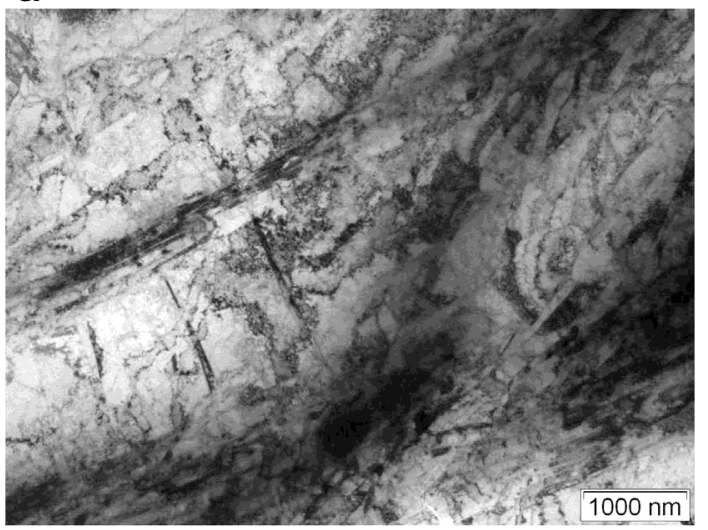

b

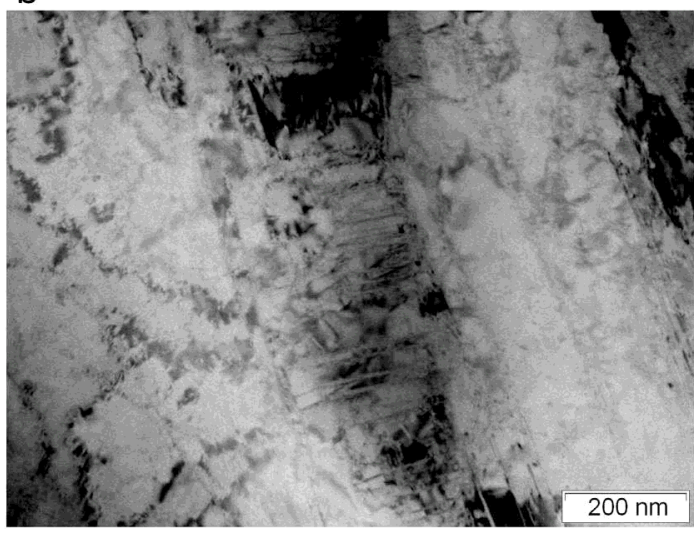

C

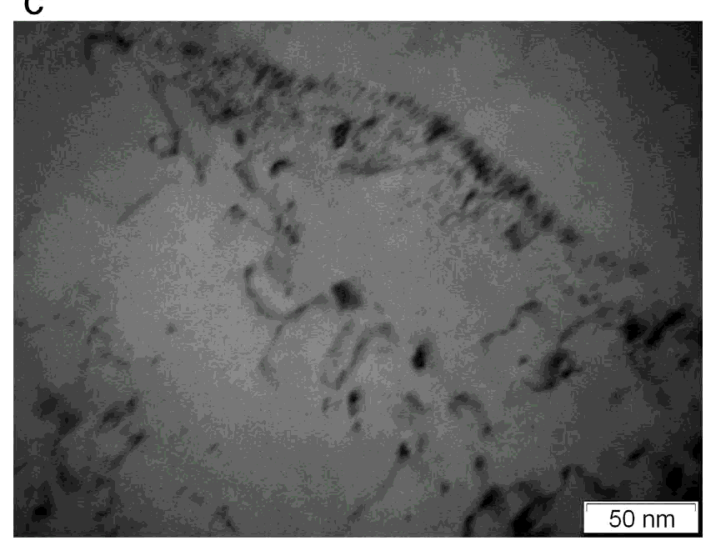

Fig. 6. TEM images showing the microstructure of the material after 4 passes of ECAP deformation at $300^{\circ} \mathrm{C}$.

when the number of pressings increased also structures at $30^{\circ}(2 \times)$ and $15^{\circ}(4 \times)$ appeared. On the sample where deformation was not performed through path $\mathrm{A}(2 \times \mathrm{RT})$, the main geometric features are quite complex and with no clear trend. No further analysis will be done on this topic on the current work.

Grain size evaluation tools proved to be quite unstable for the determination of grain size, aspect ratio, ellipses orientations, etc., because of the high heterogeneity of the microstructure. If a larger field with a larger step were used, many of the microstructural details would be lost. For this reason grain size distributions or any associated parameters were not calculated.

As it was mentioned earlier, EBSD cannot detect randomly distributed dislocations, but only those constituting arrays, by measuring the misorientation between two domains in the sample. Dislocation densities measured through EBSD and X-rays are of different nature, being the ones obtained through EBSD somehow overlapped with 


\section{RT}

ND-ED

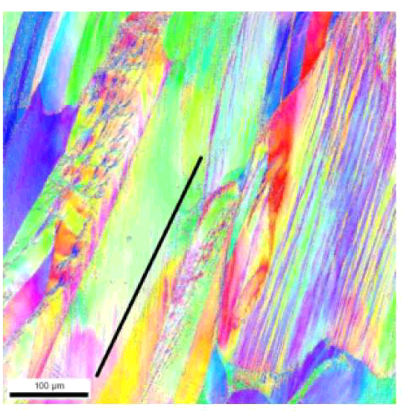

TD-ED $300^{\circ} \mathrm{C}$

\section{TD-ED}

\section{ECAP 1X}
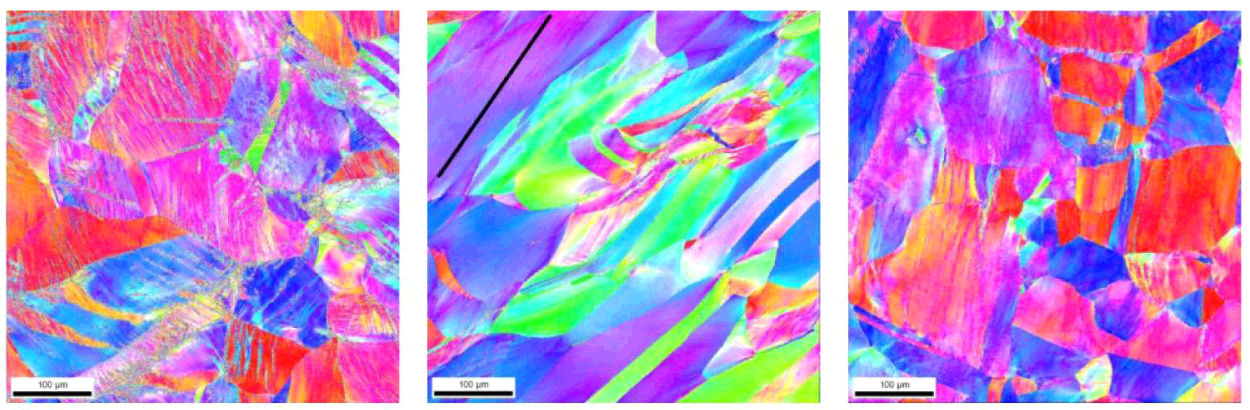

\section{ECAP 2X}
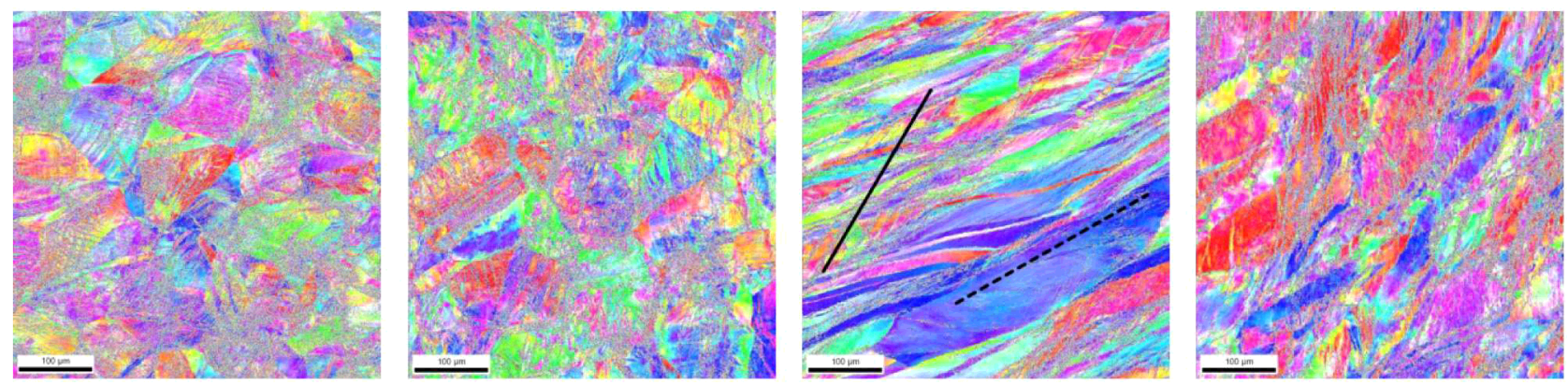

\section{ECAP $4 X$}
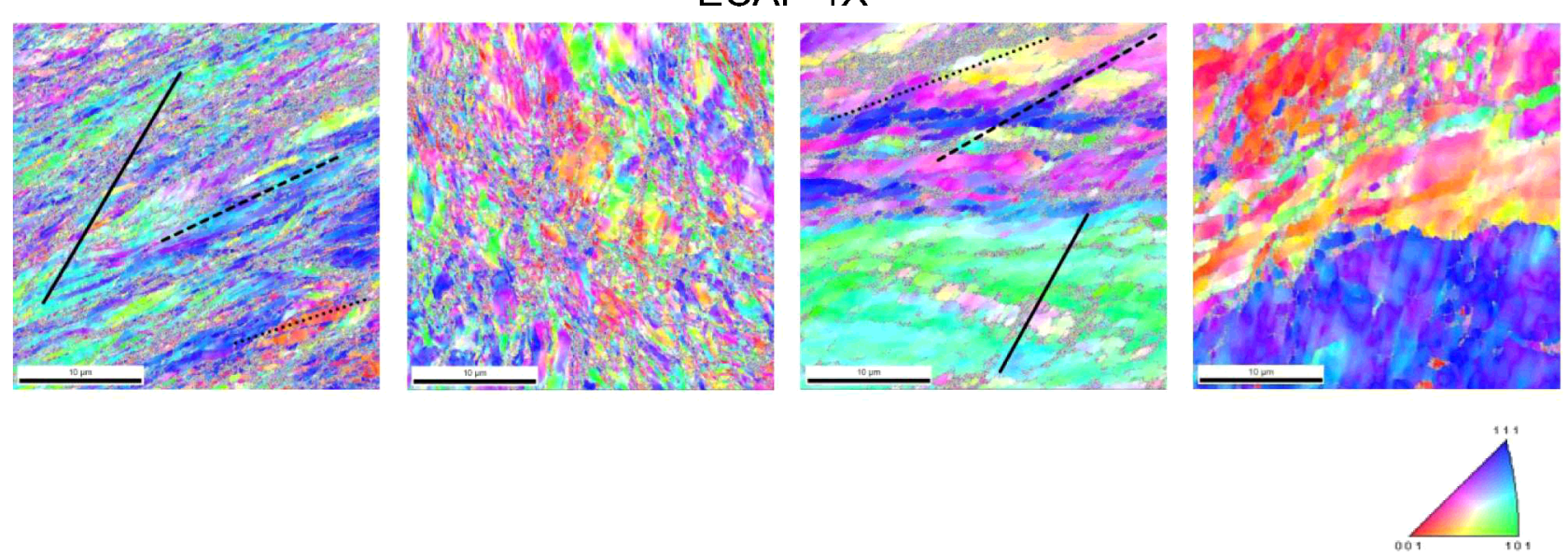

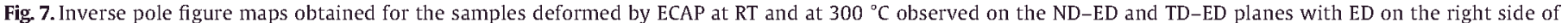
the figures. $\left(-60^{\circ},--30^{\circ}, \cdots \cdots 15^{\circ}\right)$.

certain domain limits conformed by loose dislocation arrays for which the dislocations are still discernible by X-ray techniques. Meanwhile compact dislocation arrays are only seen by X-rays as domain limits. We will not use EBSD with that purpose in the current investigation.

The Grain Boundary Character Distribution (GBCD) charts allow determining the evolution of boundaries throughout the deformation process. It can be seen in Fig. 8 that a similar behavior is observed at both deformation temperatures. The samples deformed at 1 and 2 passes at room temperature show a similar boundary proportion at both surfaces, being higher for low-angle boundaries, but after 4 passes the proportion of high-angle boundaries is similar or even higher than that for low-angle, which could be related to the reduction in grain size observed by X-ray diffraction for TD and ND. This reduction in low-angle boundaries could be caused by dynamic recrystallization occurring at this level of deformation, and would mean that the dislocations generated after this deformation are mostly arranged forming misorientation boundaries rather than being randomly distributed. Samples deformed at 1 and 2 passes at $300{ }^{\circ} \mathrm{C}$ present a higher proportion of low-angle boundaries than the samples with the same level of deformation at room temperature, but again after 4 passes there was an increase in high-angle boundary proportion.

"Grain Orientation Spread", or GOS index, was calculated to evaluate misorientation distributions, limiting the calculation to the interior of the grains in an attempt to establish a correlation with the dislocation distributions that can be determined by XRD. The results are presented in Fig. 9, and they show a similar behavior in both planes for all the 

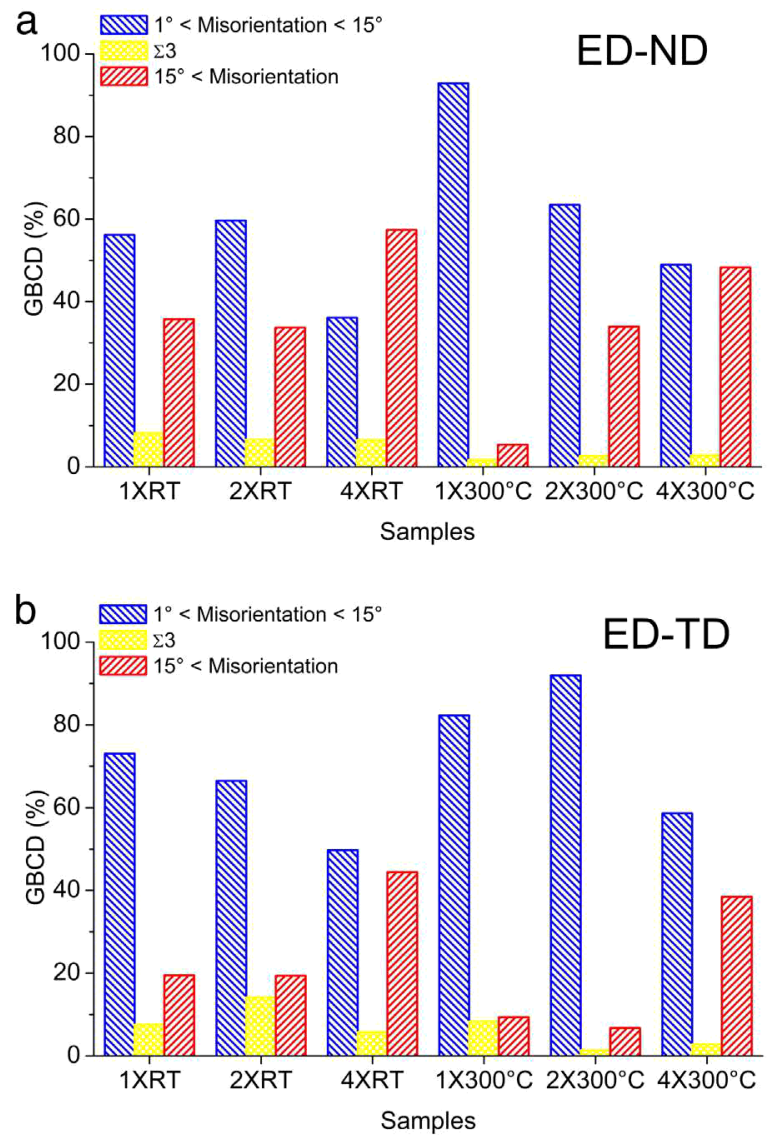

Fig. 8. GBCD charts obtained from EBSD scans on planes a) ED-ND and b) ED-TD.

samples. The values obtained for the samples deformed at RT increase from about 1.4 to 1.6 from 1 to 4 passes, which indicates that the grains, although they become smaller, develop very little misorientation boundaries inside them after the first pass (Fig. 9). A different behavior was registered for the samples deformed at $300{ }^{\circ} \mathrm{C}$, where the GOS values increased with higher deformation up to a value similar to the one registered for the sample deformed at 4 passes at RT, indicating that the grains develop internal misorientation at a different pace. On the ED-TD plane the misorientation develops faster from 1 to 2 passes and slower from 2 to 4 passes.

Finally, EBSD was used also to estimate the stacking fault density variation with increasing deformation; as it was observed in TEM images, the samples present twin boundaries further divided by nano-

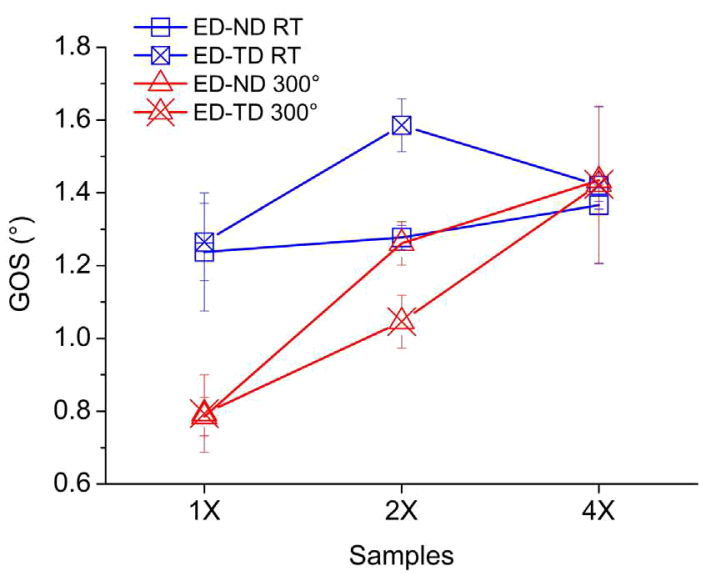

Fig. 9. Grain orientation spread on two mutual perpendicular sections (ED-ND and EDTD) for each sample at both temperatures.

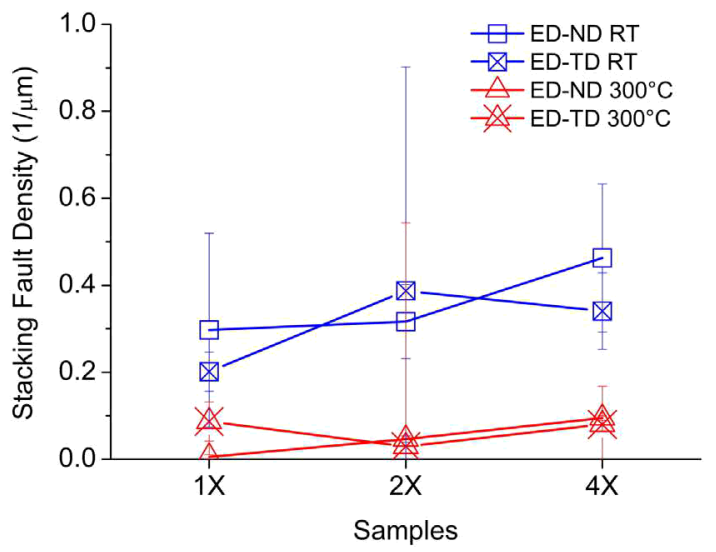

Fig. 10. Stacking faults density determined by EBSD on two mutual perpendicular sections (ED-ND and ED-TD) for each sample at both temperatures.

twins. Considering the resolution of the microscope only an estimation of the density of the larger twins can be obtained (Fig. 10).

\subsection{X-ray diffraction}

The Modified $\mathrm{W}-\mathrm{H}$ method was used to estimate grain sizes and dislocation densities. The contrast factors to be used in the calculations are not known, partially because the elastic constants of the current material are not known either; however, the values for $C_{11}, C_{12}$ and $C_{44}$ for steels with similar compositions allowed to estimate initial values of these constants for the fitting procedure [39] (e.g.: $\mathrm{C}_{11}=204.6 \mathrm{GPa}$, $\mathrm{C}_{12}=137.7 \mathrm{GPa}, \mathrm{C}_{44}=126.2 \mathrm{GPa}$ ). For the $\mathrm{W}-\mathrm{H}$ method, the instrumental contribution to the diffraction patterns was accounted for by the application of Caglioti's equation [40] to the $\mathrm{LaB}_{6}$ measured pattern, while for CMWP instrumental files were created according to the software requirements

The results work as starting guidelines for further analysis by more accurate methods. As it was mentioned earlier, the results for microstructural characteristics obtained using $\mathrm{W}-\mathrm{H}$ are not reliable for a quantitative analysis, and are only presented in this paper for a qualitative comparison with CMWP results in Figs. 11 and 12. Some of the errors are not visible in the graphs because they are smaller than the size of the points used to plot the data. The behavior of the samples deformed at both temperatures is quite different. At RT, one pass through the die resulted in similar domain sizes along TD and ND, and a smaller size for ED, but after 2 and 4 passes the grains became equiaxed, being about $50 \mathrm{~nm}$ for 4 cycles and even smaller for the sample deformed in 2 cycles, which could be related to the $90^{\circ}$ rotation imposed to the sample before the second pass in route $\mathrm{Bc}$. A different behavior was observed in the samples deformed at $300^{\circ} \mathrm{C}$, where after one pass the domains along TD and ND were larger than $200 \mathrm{~nm}$, and after increasing deformation these sizes were reduced, but were still different from the size along ED. Both W-H and CMWP methods show similar behavior. On the few TEM micrographs where the dislocation arrays are clearly visible (v.g. Fig. 4 (b) for $2 \times$ RT or Fig. $6\left(\right.$ b) for $4 \times 300^{\circ} \mathrm{C}$ ) the distance between compact arrays is nearly in coincidence with the calculated domain sizes, for what we can interpret that when the arrays become highly compact they are undistinguishable from subgrain boundaries and they are characterized as domains by XRD techniques. However TEM micrographs cannot easily provide data with enough statistical accuracy.

Regarding the dislocation densities, as it is known, W-H approach cannot provide, even approximately, dislocation densities and $M$ values from Eq. (1), simultaneously. Some assumptions must be done about the compactness of dislocation arrangements and their nature and typical $M$ values from the literature can be used. We approached the problem by a sort of "tuning" of the values by using the values 

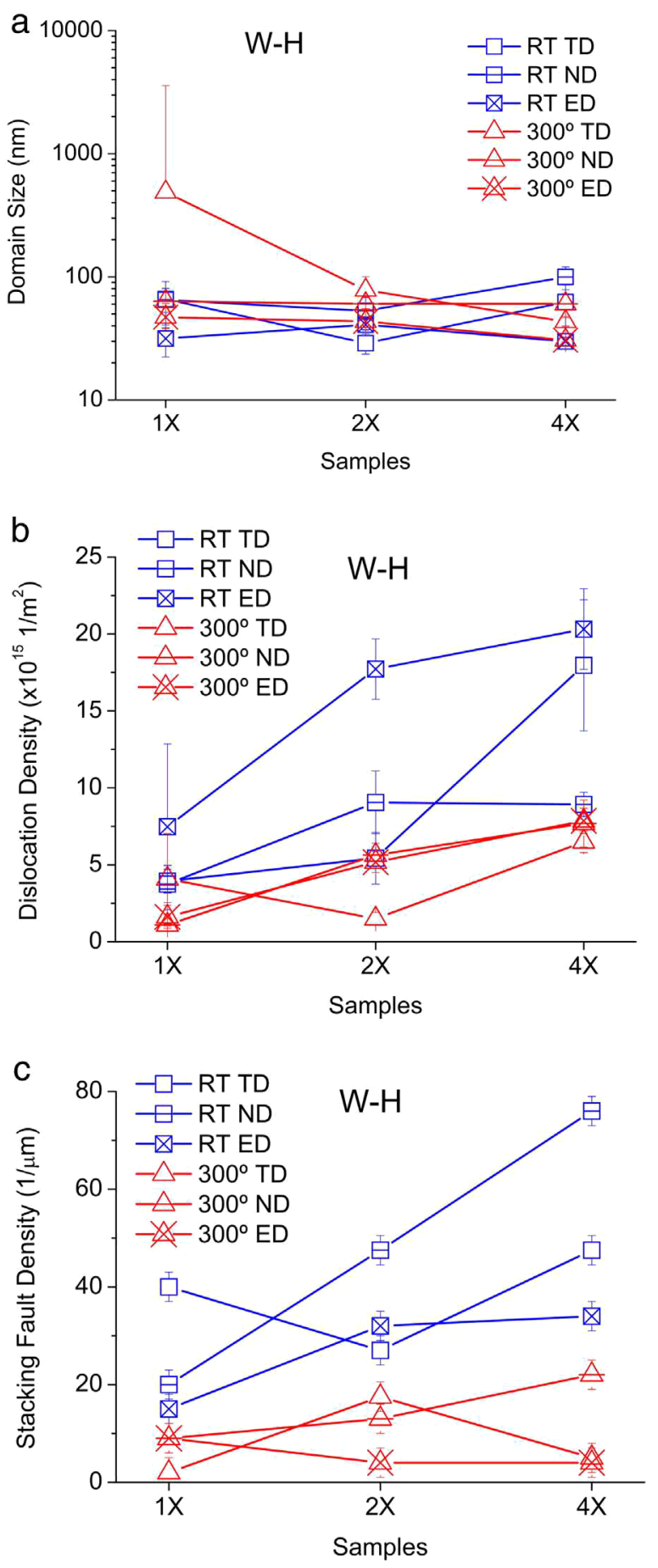

Fig. 11. Results obtained for the samples deformed at RT (blue) and at $300{ }^{\circ} \mathrm{C}$ (red) using $\mathrm{W}-\mathrm{H}$ method.

of the $M$ parameters obtained by CMWP and the proportionality factor $1 / e^{2}$ between the dislocation effective cut-off radius $R_{e}{ }^{*}$ and $R_{e}=e^{2} R_{e}{ }^{*}$ previously used as the effective outer cut-off radius of dislocations by a few authors [41-43]. That proportionality factor happens to contemplate three different levels of deformation and two temperature regimes, making both, $\mathrm{W}-\mathrm{H}$ and CMWP results, quite similar, which supports the validity of $\mathrm{W}-\mathrm{H}$ method as a fast evaluation tool.

However a discussion about the validity of the current evaluation protocol is deserved to draw some attention to the possible influence of the presence of texture in the current materials. When the orientation
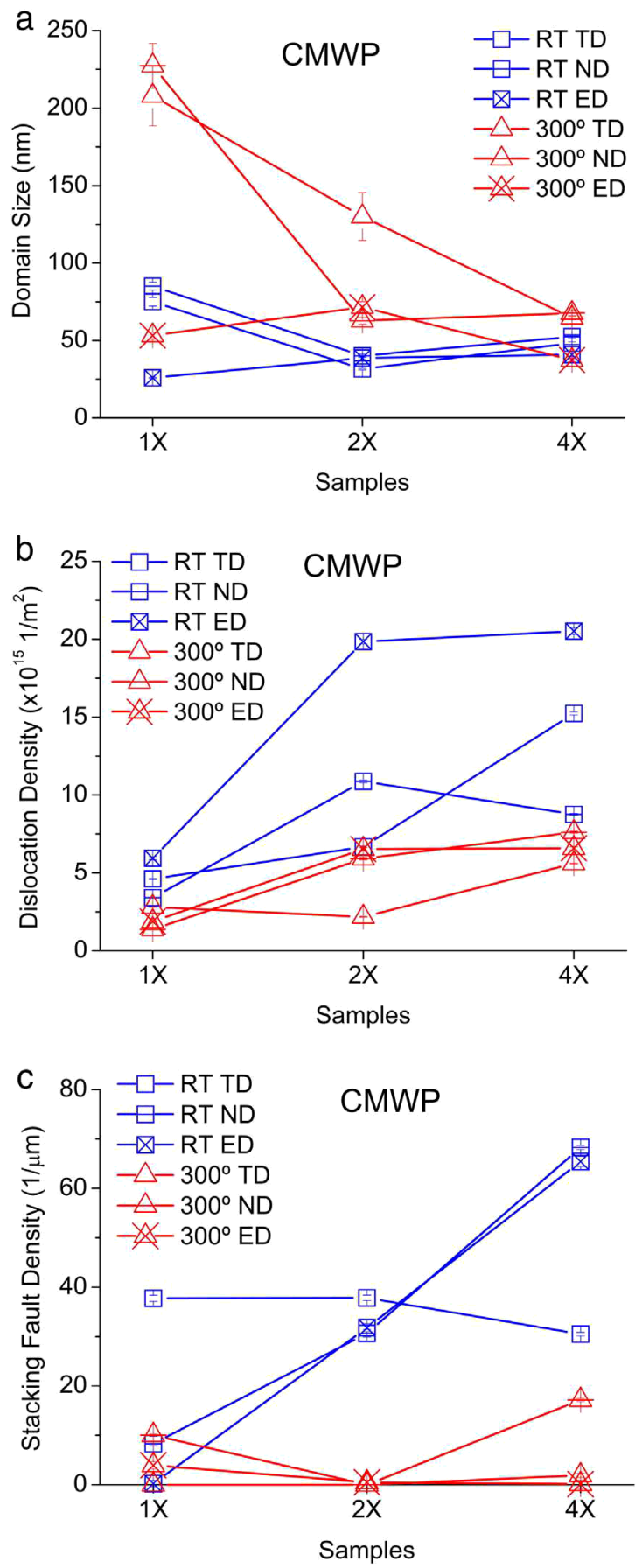

Fig. 12. Results obtained for the samples deformed at RT (blue squares) and at $300^{\circ} \mathrm{C}$ (red triangles) using CMWP method.

distribution of crystals is not random the tactic of calculating average contrast factors does not hold because the actual average must be done over the total product $\rho C$ considering the preferential orientation of the crystals. Those calculations cannot routinely be performed yet but, only in a few particular cases, some assumptions could be made to better analyze the data [44]. In the current case the textures correspond to typical preferential orientations obtained by shearing where the strengths are not too high and the components are not highly developed. The crystals achieve quite unstable orientations, always changing not only because of the sample rotation between each pass but also because of the macroscopic spin involved in shearing velocity gradient [45]. The calculations will be done on the assumption that the influence of texture is negligible, which seems 
to be confirmed by the behavior of modified W-H plots, which showed that a single curve was able in each case to closely fit experimental points except for minor deviations. In any case, we must keep in mind that the possible influence of texture is limited to the dislocation densities; domain sizes and twins are calculated independently of that assumption.

The dislocation densities increase for all samples at both temperatures and as measured along all directions from 1 to 4 passes, being this increase larger for the samples deformed at RT (Figs. 11 and 12(b)). These results imply that deforming at $300{ }^{\circ} \mathrm{C}$ favors the mobility and annihilation of dislocations and, on the contrary, at RT the accumulation of defects is, right from the first pass, highly influenced by dislocation trapping because of the presence of twins.

The results obtained for stacking fault densities are presented in Figs. 11 and 12 (c), and again the behaviors observed for both temperatures are quite different. At $300{ }^{\circ} \mathrm{C}$ the values are small, as expected [8, 9]; at RT, the stacking fault density increases from 1 to 4 passes along ND and ED but remains almost the same for TD. This situation can be understood considering that, since the deformation followed route $\mathrm{A}$, the shear planes involved in the deformation are parallel to TD and do not intersect this direction, therefore it is not expected to observe any change regarding stacking fault density in this direction; however, the value after 1 pressing is higher in this direction than in the other ones, showing perhaps the initial activation of pairs of twins intersecting each other. Two cycles through route $\mathrm{Bc}$ lead to a similar stacking fault density in all directions, which is related to the rotation introduced in the shear planes involved in the deformation process, leading also to the grain refinement and equiaxiality mentioned before.

As it was mentioned earlier, the average contrast factors of dislocations are related, besides crystal structure and elastic constants, to the edge or screw character of the dislocations present in the sample; therefore, an analysis on the $q$ value would allow estimating the proportion of each type of dislocations for increasing ECAP deformation. According to Fig. 13(a), the results obtained for the samples deformed at RT are quite similar for both models, showing that after 1 ECAP pass the character of the dislocations stored in each direction was different: while along TD both types were present in almost the same proportion, along ND and ED mainly edge and screw dislocations were present respectively. CMWP also provides values showing the same trend for the 1 ECAP sample deformed at $300^{\circ} \mathrm{C}$. After 2 and 4 cycles all directions tend to similar proportions of both types, and in all cases the values obtained by W-H were smaller than those determined by CMWP, corresponding to a higher proportion of edge dislocations. The behavior observed for the samples deformed at $300{ }^{\circ} \mathrm{C}$ show a tendency similar to RT deformation, but the values obtained from $\mathrm{W}-\mathrm{H}$ are even lower than the CMWP results, mostly in the rank that is assumed to correspond to high-mid proportions of edge dislocations. These results might imply that $\mathrm{W}-\mathrm{H}$ attempts to characterize the domains mostly as very compact arrays of edge dislocations (according to Mughrabi's model [46]), while CMWP would have a higher sensitivity to detect screw dislocations whether or not they are arranged into boundaries. According to Ungár et al. [22], low SFE materials are more prone to develop screw dislocations, which could be related to the ability of screw dislocations to overcome stacking faults during deformation [47-49]. According to the references, one of the most favorable deformation mechanisms in the presence of stacking faults is the dissociation of dislocations into partials, where at least one of them is of pure screw character; such dislocation can then cross the stacking fault during the deformation process. This lower energy process might favor the presence of a higher proportion of screw dislocations.

After 4 passes at RT the $q$ parameters are quite similar along the three sample directions. As $q$ is the main parameter influencing the value of $C_{A v}$ we can infer that there is a different accumulation of dislocations along the three sample directions, forming different compactness arrays but for very similar proportions of dislocations of both character (edge or screw) (Fig. 13).
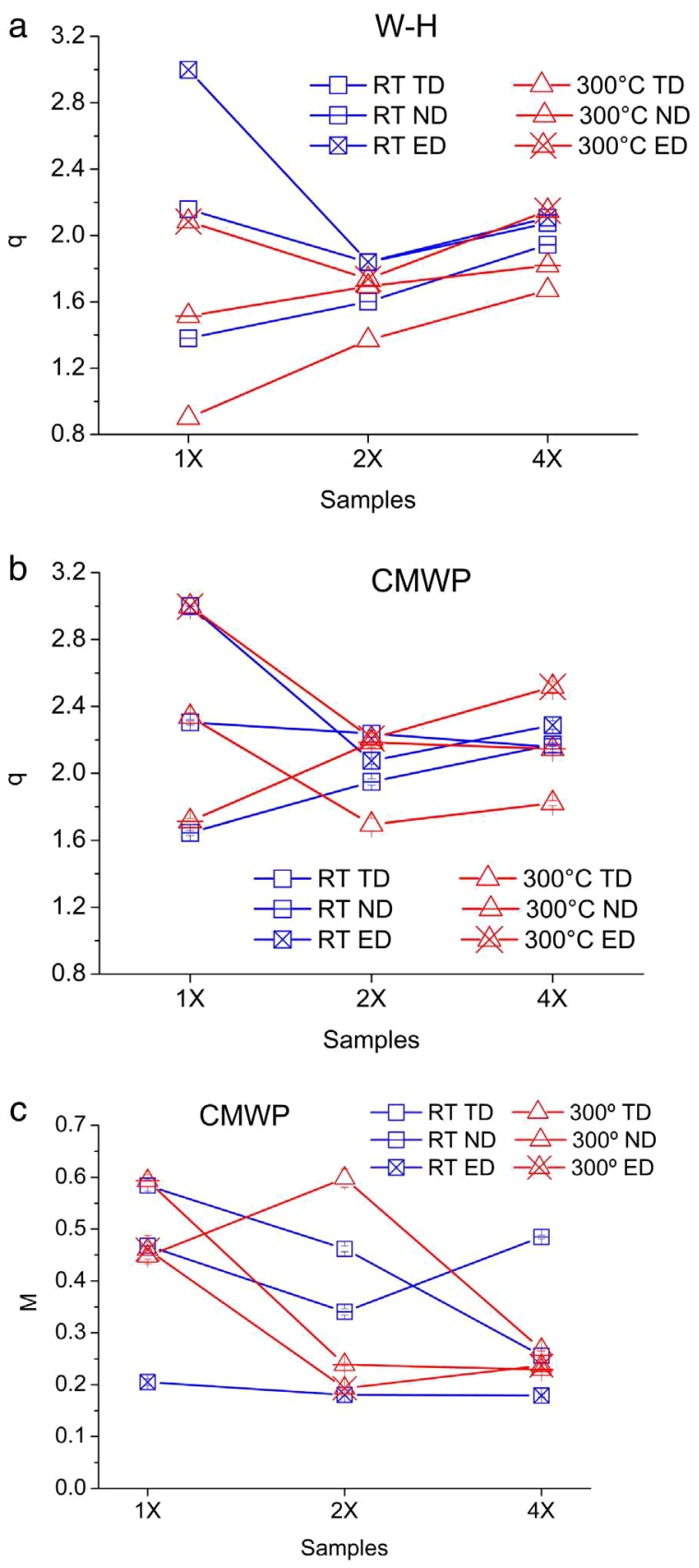

Fig. 13. $q$ parameter determined by W-H (a) and CMWP (b) models for samples deformed at RT and $300^{\circ} \mathrm{C}$, and (c) dislocation arrangement parameter M. Larger $q$ corresponds to higher contents of screw dislocations. Lower $\mathrm{M}$ values indicate higher compactness of dislocation arrays.

\section{Discussion}

The plots in Figs. 14 and 15 show the dependence of the dislocation density and stacking faults vs. domain sizes, dislocation arrangement parameter and $q$ value, in an attempt to determine the correlation between the various microstructural variables determined by the models. Dislocation densities vs. diffraction domain sizes are plotted in Fig. 14(a); samples deformed at RT exhibit domain sizes smaller than $100 \mathrm{~nm}$ and a dislocation density $\sim 5-20 \times 10^{15} \mathrm{~m}^{-2}$, while at $300^{\circ} \mathrm{C} \mathrm{de}-$ formation domain values reach $250 \mathrm{~nm}$. The general conclusion would be that the larger the domain size, the smaller the dislocation density. A similar behavior was registered in the dependence of the stacking fault density on the domain size (Fig. 15(a)), which is related to the 

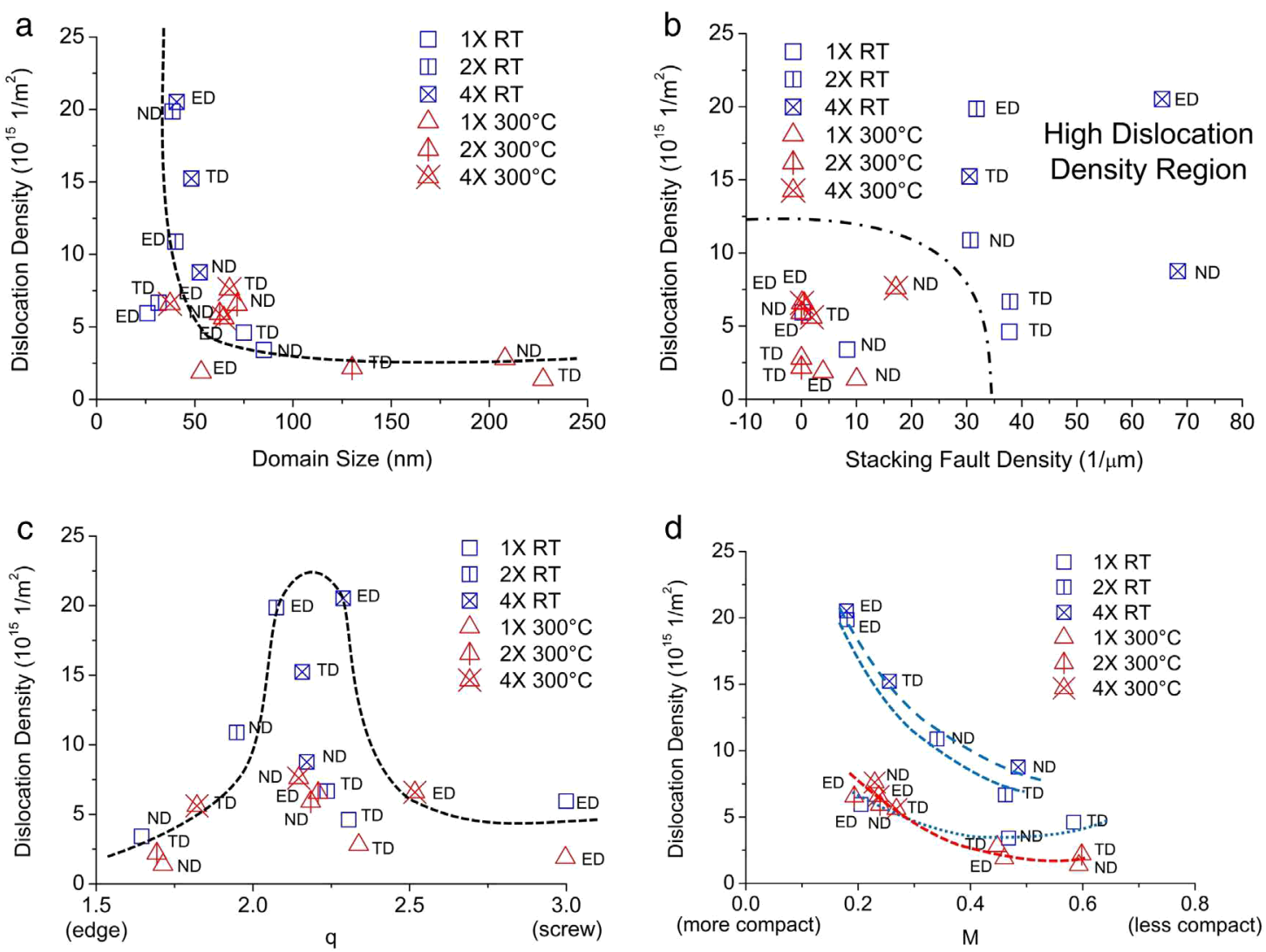

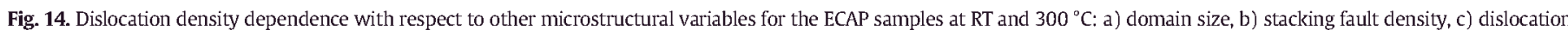
character parameter $q, \mathrm{~d}$ ) dislocation arrangement parameter $M$ (dot and dash lines are only eye guides).

fact that deformation at low SFE materials promotes a strong dislocation trapping and fragmentation by dislocation arrays. This situation can be observed in Fig. 14(b) where at $300^{\circ} \mathrm{C}$ deformation both, stacking faults and dislocation densities, are lower than those at RT when the dislocation density increases along with the stacking fault density. The $q$ factors calculated for these samples (Figs. 14(c) and 15(b)) correspond to a mid-to-high proportion of screw dislocations, in agreement with the behavior described earlier.

Regarding the dislocation density and the arrangement parameter $M$, deformation at both temperatures lead to a decrease in dislocation density with an increase in $M$ and vice versa, which indicates that if the material has a high dislocation density those defects tend to arrange into compact arrays, but if the density decreases the dislocation arrays are looser. The behavior depends on the deformation temperature as shown in Fig. 14(d), where the decrease in dislocation density with $M$ value is registered for both temperatures but with different slopes.

The domain sizes and dislocation densities calculated using either technique should be consistent with the Kocks-Mecking model for grain refinement at very large strains [50]. This model considers that during deformation the domains decrease because of the arrangement of dislocations into misorientation boundaries, which delimit the fine grain structure. This dislocation kinetics can be represented through Eq. (8):

$d \rho / d o=k_{0} / b d-k_{2} \rho$

where $d$ is a cell size, considered as the mean free path for dislocations, $\rho$ is the dislocation density, $\sigma$ the yield stress, $b$ the Burgers vector and $k_{0}$ and $k_{2}$ are constants. The verification of this model would imply a good correlation between the results obtained using the mentioned techniques, and therefore a congruent global description of the microstructural evolution through deformation.

Kocks Eq. (8) reflects the dynamics of the known behavior of increasing stresses with the decrement of grain sizes and/or increase of dislocation densities. Domain sizes are certainly anisotropic because they tend to follow, at least approximately, external final macroscopic shapes of the samples and/or strain induced shapes. Despite it can be approximately described by a tensor it is not considered a physical quantity because shape is not actually a material dependent property. Dislocation density, on the contrary, is a scalar volume dependent magnitude that should not depend on the sample orientation but only on the crystal orientation with respect to the external coordinate axes, current and also past, because of the dislocation density evolution, and only for each texture component would be shown as a sample orientation dependent magnitude. However, dislocation densities, as determined by the current state of the art approaches, vary with respect to the sample axes, i.e. TD, ND and ED. That might be consequence of the averaging effect produced by the assumption of the absence of texture, inherent to the use of average $C_{A v}$ contrast factors, despite that the texture is not negligible. In fact, in some crystalline directions, no matter how large the dislocation content can be, they might be impossible to detect by X-rays. In such case no contrast factor is able to reverse the invisibility effect.

To check the validity of Eq. (8) (Kocks-Mecking model), we would need a more continuous experimental evaluation of domain sizes and dislocation densities for being able to calculate derivatives. Only the general behavior can be evaluated if we assume that domain sizes and dislocation densities obtained using $\mathrm{W}-\mathrm{H}$ and CMWP can be averaged over all 3 directions for each sample and then plotted against the yield strength.

Yield stress should follow meanwhile some inverse of the domain size law, either like $1 / \rho$ or $1 / \rho^{1 / 2}$ as stated by Hall-Petch 

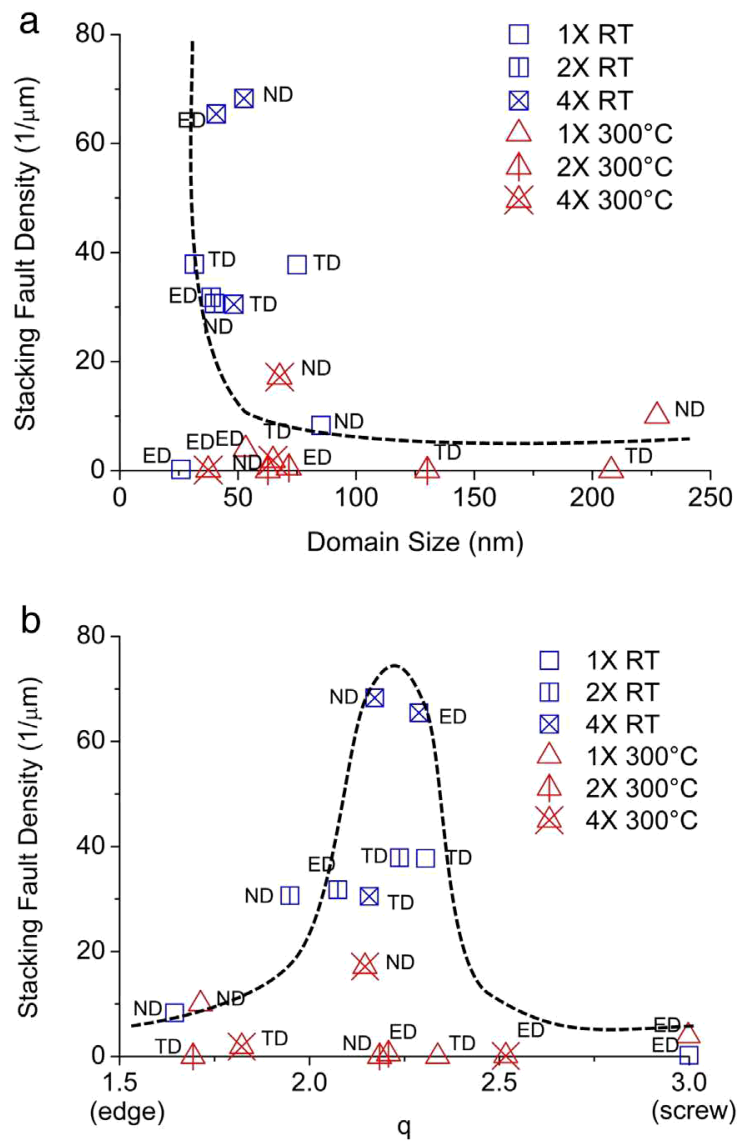

Fig. 15. Twin density vs. domain sizes a) and vs. $q$ factor b) for ECAP deformed samples at RT and $300^{\circ} \mathrm{C}$ (dot and dash lines are only eye guides).

approach [51,52]. As it is seen in the graphs, yield strength increases with diminishing domain sizes and increasing dislocation densities, which is consistent with the expected behavior (Fig. 16).

Regarding the microstructural anisotropy, the defects detected along different sample directions are qualitatively and quantitatively different, reflecting a macroscopic anisotropy probably developed by the simultaneous influence of single crystal plastic anisotropy, texture evolution and macroscopic strain rate symmetry. In this last case, the sampling capability in different directions is selectively collecting data from different texture components, all of them averaging many orientations around an axis along the measured direction for what perhaps the validity of the model is sustained when not too severe textures are present. In fact, the detected anisotropy is not an actual anisotropy case, because the parameters are all scalar magnitudes, but instead a case of heterogeneity, where the heterogeneous distribution is governed by texture. In terms of the mentioned anisotropy, it is worthy to analyze the different characters of the two main microstructural defects accumulated in the material, although they are highly correlated due to the deformation mechanisms that give rise to the microstructure:

a) Grain size is mainly related to the external strain field history. Grains tend to be elongated, either as flat "pancake" or "chocolate bar" shapes, depending on the strain path undergone by the sample, although they also tend to develop fragments inducing somehow equiaxial sub-grains. Grain sizes, and shape, are not intrinsic physical material properties, for what they cannot "a priori" depend on crystal orientation. To complicate the matters further, in the current case the elongated shapes are oriented along changing axes with respect to $E D$. In the current case the orientation of the meso-micro structure, as judged by EBSD, is not in agreement with
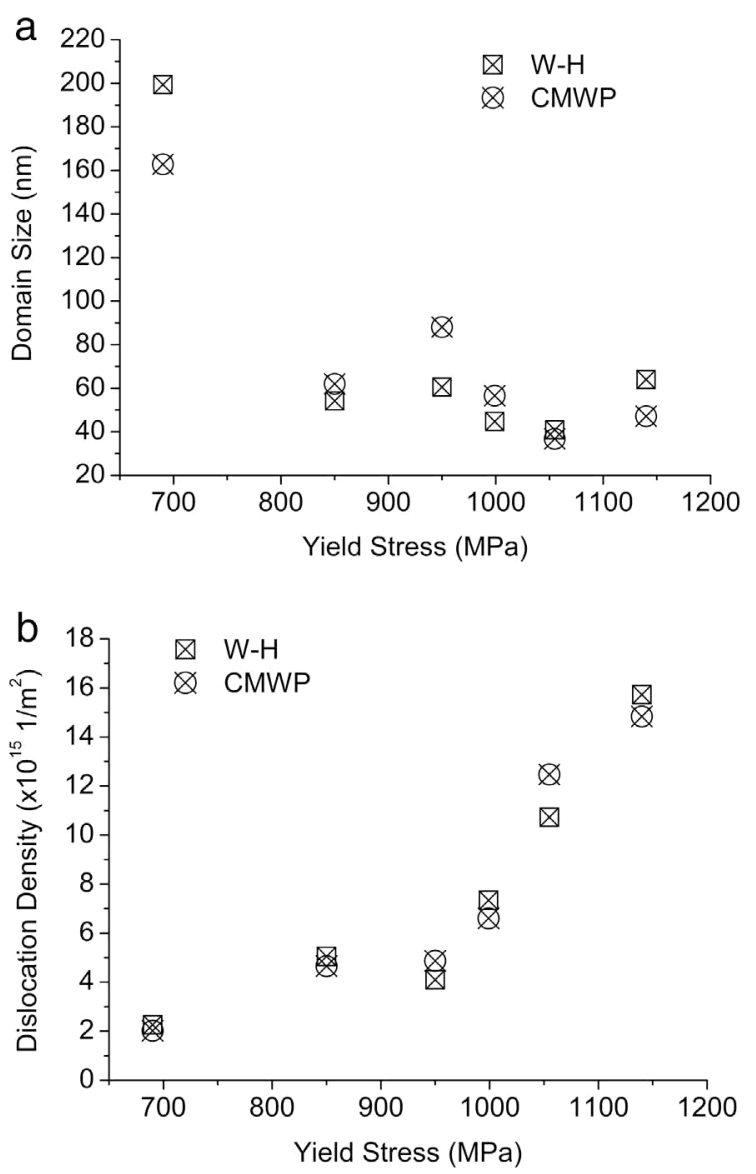

Fig. 16. Yield stress vs. (a) domain size and (b) dislocation density. The relationships between the variables agree with Eq. (8), where increasing yield stresses are due to increasing dislocation densities and decreasing average domain sizes.

the usual continuum based predictions of the literature.

b) Dislocation and SF densities are intrinsic physical quantities that depend on the micromechanical mechanisms active during deformation. They are orientation dependent quantities and develop accordingly. Besides being evident in single crystal experiments, the orientation dependence clearly arises when the polycrystalline aggregate develops texture that allows the determination of orientation dependent density quantities. However the current state of the art on determination of orientation dependence of microstructure development has still some unknowns and difficulties regarding data processing. Dislocations tend to arrange in compact arrays that soon become undistinguishable from grain boundaries, from what there might be some kind of interaction between both quantity categories that tend to obscure both phenomena.

\section{Conclusions}

The evolution of the microstructure of an F138 austenitic stainless steel deformed by ECAP was studied combining TEM and EBSD techniques and, mainly, XRD through peak broadening analysis. Deformation at RT caused the original grain subdivision into subcells and twined regions. At increasing strain secondary twinning is activated and starts to compete with dislocation glide, contributing both to grain refinement. This refinement takes place at lower equivalent deformation at RT than at $300^{\circ}$, but after 4 passes through the ECAP die the domains become equiaxed for both temperatures. XRD analysis and EBSD showed that dynamic recrystallization has begun at 4 passes at RT, what is evident by an increasing number of high-angle grain boundaries and the increase in domain size along ED. 
The combination of TEM and both diffraction techniques (EBSD and XRD) resulted in a very complete analysis of the microstructure of the material, combining statistical average information with local orientation data. The results obtained using XRD are sensitive to crystalline misorientations and residual micro-stresses caused by dislocations and stacking faults, which cannot be accurately calculated by EBSD. However, grain boundary character can be assessed using EBSD, which leads to an understanding on the development of grain boundaries and dislocation arrangements.

From the many correlations obtained for the different fitting parameters and physical variables we can remark the following:

a) Dislocation densities are higher for small domain sizes. When the arrays start being too compact they become undistinguishable from grain boundaries and the domain size is diminished accordingly. Small domain sizes are those where the dislocation arrays were more compact and the grains became fragmented.

b) The largest dislocation densities are achieved with the simultaneous activation of the twins. Dislocations become entrapped between twins and double twins making a very fine microstructure.

c) There is a trend to have higher dislocation densities for even proportions of edge and screw dislocations, which is in coincidence with a larger amount of twining.

d) The largest proportions of screw dislocations are always correlated with twins present in large numbers, probably due to the easy twin crossing mechanism provided by dislocation dissociation in partials of screw character [22,47-49].

e) Stacking fault densities, as determined by EBSD are two orders of magnitude lower than the values obtained using X-rays. That is one order of magnitude larger than the apparent lack of resolution of the technique in comparison with the actual feature dimension, tens of $\mathrm{nm} v \mathrm{vs}$. $\mathrm{nm}$. It is speculated that the interaction between twinning and dislocation storage would somehow rapidly deteriorate the plane-angle rule for twin identification by EBSD.

f) The correlations found between the many microstructural parameters bring confidence on the main assumptions of the analysis, particularly on the proposal of low texture influence on the contrast factors. Their behavior need to be further analyzed to withdraw some more microstructure insight on the deformation processes.

\section{Acknowledgments}

The authors would like to thank Prof. Tamás Ungár, Prof. Adam Rêvész and Dr. Levente Balogh and the lecturers of the II XLPA course for their help in the use and applications of CMWP software. Authors would also like to acknowledge Lic. Vanina Tartalini for her hard effort on preparing the samples for EBSD analysis.

This work has been funded by the FAPESP - Brazil (Grant number 2011/02009-0); ANPCyT - Argentina, Grant PID-BID 1341 and the International Collaboration CONICET, Argentina-DFG, Germany (Resolution № : 0183/13).

\section{References}

[1] A. Azushima, R. Kopp, A. Korhonen, D.Y. Yang, F. Micari, G.D. Lahoti, et al., Severe plastic deformation (SPD) processes for metals, CIRP Ann. Manuf. Technol. 57 (2008) 716-735, http://dx.doi.org/10.1016/j.cirp.2008.09.005.

[2] S. Asgari, E. El Danaf, S.R. Kalidindi, R.D. Doherty, Strain hardening regimes and microstructural evolution during large strain compression of low stacking fault energy fcc alloys that form deformation twins, Metall. Trans. A 28 (1997) 1781-1795, http://dx.doi.org/10.1007/s11661-997-0109-3.

[3] E. El-Danaf, S.R. Kaldindi, R.D. Doherty, Influence of grain size and stacking-fault energy on deformation twinning in fcc metals, Metall. Mater. Trans. A 30 (1999) 1223-1233, http://dx.doi.org/10.1007/s11661-999-0272-9.

[4] R. Ueji, N. Tsuchida, D. Terada, N. Tsuji, Y. Tanaka, A. Takemura, K. Kunishige, Tensile properties and twinning behavior of high manganese austenitic steel with fine-grained structure, Scr. Mater. 59 (2008) 963-966, http://dx.doi.org/10.1016/j. scriptamat 2008.06.050.
[5] I. Gutierrez-Urrutia, S. Zaefferer, D. Raabe, The effect of grain size and grain orientation on deformation twinning in a Fe-22 wt.\% Mn-0.6 wt.\% C TWIP steel, Mater. Sci. Eng. A 527 (2010) 3552-3560, http://dx.doi.org/10.1016/j. msea.2010.02.041.

[6] E. Bagherpour, M. Reihanian, R. Ebrahimi, On the capability of severe plastic deformation of twinning induced plasticity (TWIP) steel, Mater. Des. 36 (2012) 391-395, http://dxdoi.org/10.1016/j.matdes.2011.11.055.

[7] E. Bagherpour, M. Reihanian, R. Ebrahimi, Processing twin induced plasticity steel through simple shear extrusion, Mater. Des. 40 (2012) 262-267, http://dx.doi.org/ 10.1016/j-matdes.2012.03.055

[8] A. Saeed-Akbari, L. Mosecker, A. Schwedt, W. Bleck, Characterization and prediction of flow behavior in high-manganese twinning induced plasticity steels: part I. Mechanism maps and work-hardening behavior, Metall. Mater. Trans. A 43 (5) (2012) 1688-1704, http://dx.doi.org/10.1007/s11661-011-0993-4.

[9] D.R. Steinmetz, T. Jäpel, W. Wietbrock, P. Einsenlohr, I. Gutierrez-Urrutia, A Saeed-Akbari, et al., Revealing the strain-hardening behavior or twinninginduced plasticity: theory, simulations, experiments, Acta Mater. 61 (2013) 494-510, http://dx.doi.org/10.1016/j.actamat.2012.09.064.

[10] H. Ueno, K. Kakihata, Y. Kaneko, S. Hashimoto, A. Vinogradov, Nanostructurization assisted by twinning during equal channel angular pressing of metastable $316 \mathrm{~L}$ stainless steel, J. Mater. Sci. 46 (2011) 4276-4283, http://dx.doi.org/10.1007/ s10853-011-5303-4.

[11] Y. Zhang, N.R. Tao, K. Lu, Effects of stacking fault energy, strain rate and temperature on microstructure and strength of nanostructured $\mathrm{Cu}-\mathrm{Al}$ alloys subjected to plastic deformation, Acta Mater. 59 (2011) 6048-6058, http://dx.doi.org/10.1016/j. actamat.2011.06.013.

[12] I.B. Timokhina, A. Medvedev, R Lapovok, Severe plastic deformation of a TWIP steel, Mater. Sci. Eng. A 593 (2014) 163-169, http://dx.doi.org/10.1016/j.msea.2013.11.013.

[13] S. Scheriau, Z. Zhang S. Kleber, R. Pippan, Deformation mechanisms of a modified $316 \mathrm{~L}$ austenitic steel subjected to high pressure torsion, Mater. Sci. Eng. A 528 (2011) 2776-2786, http://dxdoi.org/10.1016/j.msea.2010.12.023.

14] G.Z. Liu, N.R. Tao, K. Lu, 316L austenite stainless steels strengthened by means of nano-scale twins, J. Mater. Sci. Technol. 26 (4) (2010) 289-292, http://dx.doi.org/ 10.1016/S1005-0302(10)60048-5.

[15] T. Ungár, J. Gubicza, G. Ribárik, A. Borbély, Crystallite size distribution and dislocation structure determined by diffraction profile analysis: principles and practical application to cubic and hexagonal crystals, J. Appl. Crystallogr. 34 (2001) 298-310, http://dx.doi.org/10.1107/S0021889801003715.

[16] T. Ungár, J. Gubicza, P. Hánák, I. Alexandrov, Densities and character of dislocations and size-distribution of subgrains in deformed metals by X-ray diffraction profile analysis, Mater. Sci. Eng. A 319-321 (2001) 274-278, http://dx.doi.org/10.1016/ S0921-5093(01)01025-5.

[17] A.J. Schwartz, M. Kumar, B.L. Adams, Electron Backscatter Diffraction in Materials Science, 2nd ed. Kluwer Academic-Plenum Publishers, New York, 2000.

[18] P. Scherrer, Bestimmung der Größe und der inneren Struktur von Kolloidteilchen mittels Röntgenstrahlen, Göttinger Nachr. Ges. 2 (1918) 98-100 (http://gdz.sub. uni-goettingen.de/dms/load/img/?PPN=GDZPPN002505045\&IDDOC $=63709$ ).

[19] G.K. Williamson, W.H. Hall, X-ray line broadening from filed aluminum and wolfram, Acta Metall. 1 (1953) 22-31, http://dx.doi.org/10.1016/00016160(53)90006-6.

[20] B.E. Warren, X-ray studies of deformed metals, Prog. Met. Phys. 8 (1959) 147-202, http://dx.doi.org/10.1016/0502-8205(59)90015-2.

[21] T. Ungár, A. Borbély, The effect of dislocation contrast on X-ray line broadening: a new approach to line profile analysis, Appl. Phys. Lett. 69 (21) (1996) 3173-3175, http://dx.doi.org/10.1063/1.117951.

[22] T. Ungár, I. Dragomir, Á. Révész, A. Borbély, The contrast factor of dislocations in cubic crystals: the dislocation model of strain anisotropy in practice, J. Appl. Crystallogr. 32 (1999) 992-1002, http://dx.doi.org/10.1107/S0021889899009334.

[23] I.C. Dragomir, T. Ungár, Contrast factors of dislocations in the hexagonal crystal system, J. Appl. Crystallogr. 35 (2002) 556-564, http://dx.doi.org/10.1107/ S0021889802009536.

[24] G. Ribárik, Modeling of Diffraction Patterns Based on Microstructural Properties. (Ph.D. Thesis) http://csendes.elte.hu/cmwp/doc/Ribarik-PhD-Thesis.pdf 2008.

[25] P. Scardi, M. Leoni, R. Delhez, Line broadening analysis using integral breadth methods: a critical review, J. Appl. Crystallogr. 37 (2004) 381-390, http://dx.doi. org $/ 10.1107 /$ S0021889804004583.

[26] G. Ribárik, J. Gubicza, T. Ungär, Correlation between strength and microstructure of ball-milled Al-Mg alloys determined by X-ray diffraction, Mater. Sci. Eng. A 387-389 (2004) 343-347, http://dx.doi.org/10.1016/j.msea.2004.01.089.

[27] G. Ribárik, T. Ungár, Characterization of the microstructure in random and textured polycrystals and single crystals by diffraction line profile analysis, Mater. Sci. Eng. A 528 (2010) 112-121, http://dx.doi.org/10.1016/j.msea.2010.08.059.

[28] G. Ribárik, T. Ungár, J. Gubicza, MWP-fit: a program for multiple whole-profile fitting of diffraction peak profiles by ab initio theoretical functions, J. Appl. Crystallogr. 34 (2001) 669-676, http://dx.doi.org/10.1107/\$0021889801011451.

[29] M. Wilkens, in; J.A. Simmons, R. de Wit, R. Bullough (Eds.),Fundamental Aspects of Dislocation Theory, Washington DC: Nat Bur Stand Spec Publ, vol. Il No. 317 1970 , p. 1195

[30] T. Ungár, G. Tichy, The effect of dislocation contrast on X-ray line profiles in untextured polycrystals, Phys. Status Solidi A 171 (1999) 425-434, http://dx.doi. org $/ 10.1002 /$ (SICI) 1521-396X(199902)171:2<425::AID-PSSA425>3.0.CO;2-W.

[31] L.S. Mannan, C.S. Chetal, B. Raj, B.S. Bhoje, Selection of materials for prototype fast breeder reactor, Trans. Indian Inst Met 56 (2) (2003) 155-178.

[32] J.P. Strizak, H. Tian, P.K. Liaw, L.K. Mansur, Fatigue properties of type $316 \mathrm{LN}$ stainless steel in air and mercury, J. Nucl. Mater. 343 (1-3) (2005) 134-144, http://dx.doi. org/10.1016/j.jnucmat.2005.03.019. 
[33] P. Ducheyne, G.W. Hastings, CRC Series on Structure-Property Relationships of Biomaterials, CRC Press, Boca Raton, FL, 1984

[34] M. Semlitsch, in: P. Ducheyne, G.W. Hastings (Eds.), Metals and Ceramics Biomaterials, CRC Press, Boca Raton, FL 1984, pp. 1-21.

[35] Y. Iwahashi, J. Wang, Z. Horita, M. Nemoto, T.G. Langdon, Principle of equal-channel angular pressing for the processing of ultra-fine grained materials, Scr. Mater. 35 (1996) 143-146, http://dx.doi.org/10.1016/1359-6462(96)00107-8.

[36] V. Randle, Electron backscatter diffraction: strategies for reliable data acquisition and processing, Mater. Charact. 60 (2009) 913-922, http://dx.doi.org/10.1016/j. matchar.2009.05.011.

[37] V. Segal, Materials processing by simple shear, Mater. Sci. Eng. A 197 (1995) 157-164, http://dxdoi.org/10.1016/0921-5093(95)09705-8.

[38] I.]. Beyerlein, C.N. Tomé, Analytical modeling of material flow in equal channel angular extrusion (ECAE), Mater. Sci. Eng. A 380 (2004) 171-190, http://dx.doi. org/10.1016/j.msea.2004.03.063.

[39] RW. Smith, G.S. Was, Application of molecular dynamics to the study of hydrogen embrittlement in Ni-Cr-Fe alloys, Phys. Rev. B 40 (15) (1989) 10322-10336, http://dx.doi.org/10.1103/PhysRevB.40.10322.

[40] G. Caglioti, A. Paoletti, F. Ricci, Choice of collimators for a crystal spectrometer for neutron diffraction, Nucl. Inst. Methods 3 (1958) 223-228.

[41] T. Ungár, H. Mughrabi, D. Rönnpagel, M. Wilkens, X-ray line-broadening study of the dislocation cell structure in deformed [001]-orientated copper single crystals, Act Metall. 32 (3) (1984) 333-342, http://dx.doi.org/10.1016/0001-6160(84)90106-8.

[42] M. Wilkens, in: P.o. Kettunen, T.K. Lepistó, M.E. Lehtonen (Eds.), Proceedings of the 8th International Conference on the Strength of Metal Alloys (ICSMA 8), Pergamon, Tampere, Finland, Oxford 1988, pp. 125-130.

[43] M. Hecker, E. Thiele, C. Holste, X-ray diffraction analysis of internal stresses in the dislocation structure of cyclically deformed nickel single crystals, Mater. Sci. Eng. A 234-236 (1997) 806-809, http://dx doi.org/10.1016/S0921-5093(97)00370-5.
[44] T. Ungár, K. Nyilas, W. Skrotzki, Dislocation densities in soft and hard oriented grains of compression deformed textured NiAl polycrystals, Int J. Mater. Res. 99 (2008) 725-733, http://dx doi.org/10.3139/146.101691.

[45] R. Bolmaro, UF. Kocks, A comparison of the texture development in pure and simple shear and during strain path changes, Scr. Metall. Mater. 27 (12) (1992) 1717-1722, http://dx.doi.org/10.1016/0956-716X(92)90008-3.

[46] H. Mughrabi, T. Ungár, W. Kienle, M. Wilkens, Long-range internal stresses and asymmetric X-ray line-broadening in tensile-deformed [001]-orientated copper single crystals, Philos. Mag. A 53 (6) (1986) 793-813, http://dx.doi.org/10.1080/ 01418618608245293.

[47] Y. Zhu, X. Wu, X. Liao, J. Narayan, L. Kecske's, S. Mathaudhu, Dislocation-twin interactions in nanocrystalline FCC metals, Acta Mater. 59 (2011) 812-821, http://dx.doi.org/10.1016/j.actamat.2010.10.028.

[48] N. Li, J.Wang, A. Misra, X. Zhang, J. Huang, J. Hirth, Twinning dislocation multiplication at a coherent twin boundary, Acta Mater. 59 (15) (2011) 5989-5996, http://dx.doi. org/10.1016/j.actamat2011.06.007.

[49] H. Wei, Y. Wei, Interaction between a screw dislocation and stacking faults in FCC metals, Mater. Sci. Eng. A 541 (2012) 38-44, http://dx.doi.org/10.1016/j.msea. 2012.01 .115 .

[50] U.F. Kocks, H. Mecking, Physics and phenomenology of strain hardening: the FCC case, Prog. Mater. Sci. 48 (3) (2003) 171-273, http://dx.doi.org/10.1016/S00796425(02)00003-8

[51] E.O. Hall, The deformation and ageing of mild steel: III discussion of results, Proc. Phys. Soc. B 64 (1951) 747-753, http://dx.doi.org/10.1088/0370-1301/64/9/303.

[52] N.J. Petch, The cleavage strength of polycrystals, J. Iron Steel Inst. 174 (1953) 25-28 (http://garfield.library.upenn.edu/classics 1982/A1982NM35100001.pdf). 